Research Article

\title{
Subway-Induced Vibration Measurement and Evaluation of the Structure on a Construction Site at Curved Section of Metro Line
}

\author{
Weixing Shi, ${ }^{1}$ Ligang Bai, ${ }^{1}$ and Jianping Han $\mathbb{D}^{2}$ \\ ${ }^{1}$ Research Institute of Structural Engineering and Disaster Reduction, College of Civil Engineering, Tongji University, \\ Shanghai 200092, China \\ ${ }^{2}$ Key Laboratory of Disaster Prevention and Mitigation in Civil Engineering of Gansu Province, \\ Lanzhou University of Technology, Lanzhou 730050, China \\ Correspondence should be addressed to Jianping Han; jphan@lut.cn
}

Received 12 July 2018; Revised 19 September 2018; Accepted 18 October 2018; Published 2 December 2018

Academic Editor: Yuri S. Karinski

Copyright (๑) 2018 Weixing Shi et al. This is an open access article distributed under the Creative Commons Attribution License, which permits unrestricted use, distribution, and reproduction in any medium, provided the original work is properly cited.

\begin{abstract}
Metro property buildings developed rapidly in metropolitan cities over last several years in China. The subway-induced vibration, which may influence the serviceability of the buildings and the comfortability of their occupants over or near the metro lines, has been paid more and more attention by professional and academic experts. Based on the vibration measurement data of a construction site over Shenzhen Metro line No. 1, this paper utilizes the reasonable and completed data processing method to handle and analyse the measured data. Through the analysis of the data, the subway-induced vibration propagation trend of free field along the perpendicular direction to metro line was investigated. It is demonstrated that the subway-induced vibration propagation along the perpendicular direction to metro line was damped out on free field as a whole. But there may exist "rebound phenomenon" at local zones. The responses on pile top and soil adjacent to pile in the vertical shaft along three directions were investigated, and their characteristics in time and frequency domains are compared. Comparison indicates that the subwayinduced vibration on pile top is stronger than soil site near the pile. The measurement results on free field reveal that the most obvious feature of this metro line with curved section is that the vibration along the perpendicular direction is stronger than the other directions. But the measurement results in the vertical shaft show that the vertical vibration mainly transferring through the pile and pile's vibration in the vertical direction is dominant. Finally, the dynamic time-history analysis of the building model under the measured acceleration was conducted. The analytical results show that the vibration response of two evaluation indicators increases with the decrease of damping ratio along all three directions. The vertical vibration is more dominant than other two directions at each floor of building. The vibration levels decrease with the increase of story number along vertical direction and firstly decrease and then increase with the increase of story number increasing along two lateral directions.
\end{abstract}

\section{Introduction}

With the rapid development of urbanization and uninterrupted increase of population, rational plan and efficient utilization of urban land have become imperative. The estate exploitation of metro depots and vicinity adjacent to metro station, which is so-called development of metro property buildings, gradually becomes the focus of major property developers and would have a desirable prospect. The metro property buildings over or near the metro line, especially the buildings over the metro line, potentially have the problems for comfortability and serviceability which were induced by subway. The subwayinduced vibration propagates to structures above the tunnel through rails and via track beds, piles, and soil covered tunnels when metro vehicles pass. The subwayinduced vibration leads to the vibration and noise of the structure, which are undesirable environmental issues and can cause occupants' discomfort and impair the commercial value of the residences when the vibration level exceeded the certain limits. For example, according to field test of vibration of metro depot of one city in China, the vibration level of residential buildings rightly over the metro depot reached $85 \mathrm{~dB}$ when subway passes at the 
speed of 15 20 km per hour, where it caused the complaint from the occupants [1].

Environmental vibration induced by subway or other rail traffic is a type of vibration between the deterministic and random vibration. The determinacy is that marshalling and model of train are almost unchanged and the sleeper spacing is also determined. The randomness is that tread of wheel and track is distributed randomly, and underground geotechnical condition is complex, and the weight of the train is also changed. It is difficult to accurately determine the impact of the environment vibration induced by metro, meanwhile the analysis should be combined with field measurement.

Hassan [2] investigated the propagation of groundborne vibration due to surface trains and subway. It was found that the vibration propagates mainly through compression waves with particle motion in the direction of propagation, shear waves with particle motion perpendicular to the direction of propagation, and surface waves with the elliptical particle motion in a vertical plane. Yang and Hung [3] reported that many factors cause the vibration of the tunnel structure when the subway passed through the tunnel, including the load generation mechanism of the train-track system, the geometry and location of the tunnel structure, and the irregularity of the soil layers. The magnitude of the vibration from the soil into the building depends on the degree of coupling between the soil and the foundation. When the vibration propagates from the soil to the foundation, the energy of the interface is reflected due to the mismatch or changing of impedances between two medium which results in a decrease of the vibration level $[4,5]$. When the base plate of building and soil is in full contact, the coupling loss is determined to be $0 \mathrm{~dB}$ for frequencies lower than the resonance frequency of the plate, and the vibration of the base plate is similar to the soil [6]. The coupling loss for lightweight buildings and buildings supported directly on rock is $0 \mathrm{~dB}$, and for other base types, it changes among $2 \sim 15 \mathrm{~dB}$ due to the diversity of the frequency domain and base types [7]. This explained the reason that vibration levels inside some buildings are lower compared to measurements in open fields.

Some field vibration measurements are carried out on different zones. For example, Chen et al. [8] shed new light on the acceleration characteristics of vibration induced by train in the seasonally frozen region of Daqing in China and conveyed that the vertical component is prominent. Wei et al. [9] measured the subway-induced vibration for a tunnel and a 6-story masonry building over the tunnel in Shanghai and reached the similar conclusion. The subwayinduced vibration in a building on the subway platform was measured to find that vibration signal propagates mainly along the pile-column path to upper floors [10]. The above research studies were all focused on subway-induced vibration at straight segment of metro line, and the vertical component is conspicuous. For a curved section of the metro line, subway-induced vibration of a free field or structural base potentially has different situations, and the horizontal component of subway-induced vibration is also necessary to be noteworthy concerned. On the metro-induced field vibration measurements, several researchers investigated the vibration transmission in the metro depot and the over-track building or nearby building [11-14]. The research on vibration of over-track building related the curved section of metro line, but the vibration is not obvious because the speed of metro is less than $10 \mathrm{~km}$ per hour.

Also, many numerical studies had been done on the subway-induced vibration. Zhou et al. [15] made a numerical study on an over-track building and shown that vibration serviceability of the first floor cannot meet the requirement, and some vibration reduction measures should be taken. The substructuring approach, one of 3D FEM methods, was adopted to predict vibrations of the building due to subway traffic. The coupling of the building to the ground is established by taking into account the soilstructure interaction (SSI) [16-18]. Lopez-Mendoza et al. [19] presented a scoping model that can predict groundborne railway vibration levels within building typically required to analyse a complex SSI problem and thus provide a practical tool to rapidly analyse the vibration response of numerous buildings near railway lines. Also, a coupled finite element-boundary element methodology was employed to analyse the interaction between a building and a railway tunnel at the surface of a homogeneous half space, respectively [20]. Although these above numerical methods or models are relatively accurate, the computational cost is too high. The research studies on combination between numerical simulation and in situ measurement were carried on the problem of subway-induced vibration [21-23].

This research mainly includes two parts. In the first part, firstly, the vibration measurements were carried out on a construction field over a curved segment of Shenzhen Metro line No. 1, and measurement points were set on free field and in the vertical shaft. Secondly, the measured acceleration was operated by reasonable data processing technology, including removal of background vibration which was emphasised, and then the dynamic time-history responses of acceleration, velocity, and displacement at the measurement points in three directions were obtained. Fourier transform technology (FFT) was used to gain the vibration characteristics of timefrequency domain of measurement points. Finally, from the perspectives of time and frequency domain, the vibration prorogation trend of free field in three directions was analysed, and the subway-induced vibration between pile top and soil site near the pile is compared. In the second part, the analysis was concentrated on the vibration analysis of the substructure. Based on the structure model of the building to be built over the vertical shaft and the measured accelerations of the pile as the excitation to the base, the influence of damping ratio on average vibration level of the evaluation points at each floor was studied. The distribution of the average vibration level along the high-wise of the building was also reported.

\section{Field Vibration Measurement}

Although there was already a lot of field measurements on the vibration induced by rail transit, it is well known that the complexity of the soil itself, the variability of the regional sites, and the randomness of the rail transit vibration will cause local 
differences of subway-induced vibrations. Carrying out field vibration measurement is quite necessary in order to more reliably predict the vibration level of the proposed building.

2.1. Arrangement of Measuring Points. The vibration measurement was executed, and the measuring points were arranged on the free field and in vertical shaft of a construction site over the curved segment of Shenzhen Metro line No. 1 where a building complex will be built. The vibration measurement includes two parts. The first part was executed on a free field that its elevation is $\pm 0.00 \mathrm{~m}$, and the specific measuring point diagram is shown in Figure 1. Four measuring points were arranged along the radial direction of metro line which is perpendicular to forward direction of metro line. The distances from the 4 measuring points (W1, $\mathrm{W} 2$, W3, and W4) to the right metro line (the upper line in the Figure 1) are $15 \mathrm{~m}, 27 \mathrm{~m}, 36 \mathrm{~m}$, and $45 \mathrm{~m}$, respectively. The second part was executed in vertical shaft where bearing test of uplift pile was carried on. The elevation of top of uplift pile is $-12.00 \mathrm{~m}$, and the specific measuring point diagram is also shown in Figure 1, and the field measurement photo in vertical shaft is shown in Figure 2. Two measuring points (S1 and S2) were arranged on the vertical shaft. The $S 1$ point was set on the top of the uplift pile that the diameter is $1000 \mathrm{~mm}$, and S2 point was set on the original soil away from the S1 point $4 \mathrm{~m}$. For this curved section of metro line, the curve radiuses of left and right line are $415 \mathrm{~m}$ and $400 \mathrm{~m}$, respectively. The depth from soil surface to tunnel's top is about $17 \mathrm{~m}$ and the soil parameters of different soil layers are shown in Table 1.

When subway is been driving off on this curved section of metro line No.1, the speed is under $40 \mathrm{~km}$ per hour. For left line, the running direction of metro is from down to up, and it is exactly the opposite for right line as shown as Figure 1. The running metro's type is the A-type, which has ability to carry 2500 people maximum, has 6 compartments with 36-ton weight of each one, and has $140 \mathrm{~m}$ length. The flexible soft sleeper was adopted as the wheel base to reduce the vibration effect on running metro. The diameter of tunnel is $6 \mathrm{~m}$, thickness of tunnel segment is $30 \mathrm{~cm}$, and tunnel depth is about 13.8 17.45 $\mathrm{m}$ among this section of metro line.

Each of the measuring points was mounted three acceleration sensors labelled with $\mathrm{X}, \mathrm{Y}$, and $\mathrm{Z}$ that are the identifiers of directions which are parallel to metro line, perpendicular to metro line, and vertical to ground, respectively. The following chapters all obey this naming rule.

2.2. Measuring Instrumentation. The instrumentation used the SVSA data acquisition and signal processing system in this measurement. This system that was initially developed independently by our research team in 2006 [24] has many advantages such as high sampling frequency, long working duration, portable to carry, etc. It can not only acquire the high-precision vibration signal but also fully meet the test requirements of rail transit environment vibration by powerful data processing functions.

Lance LC0132 $\mathrm{T}$ piezoelectric accelerometers (with sensitivity $49.67 \mathrm{~V} / \mathrm{g}$; amplitude range: $\pm 0.1 \mathrm{~g}$; frequency range: $0.05-500 \mathrm{~Hz}$; resolution ratio: $0.0000006 \mathrm{~g}$; weight:

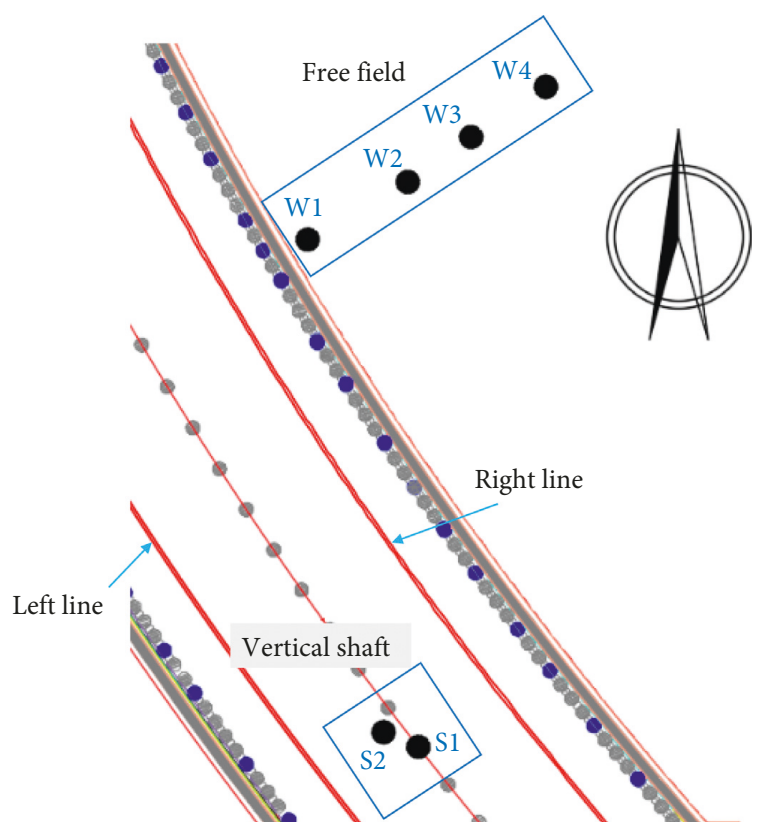

Figure 1: Measuring points of construction site.

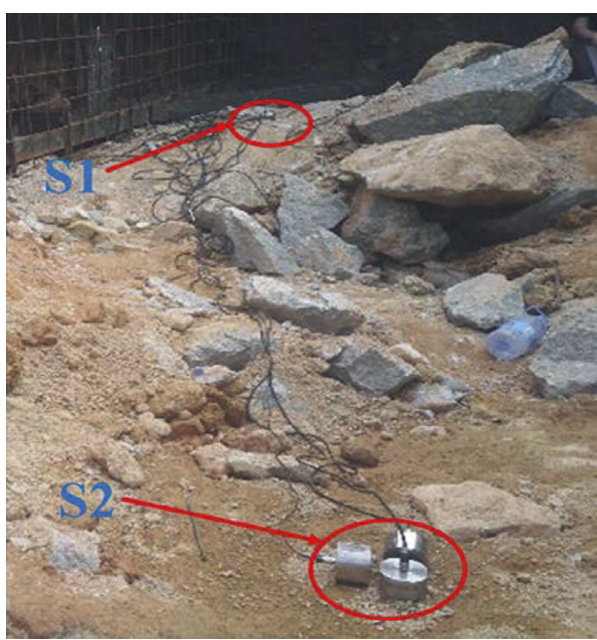

Figure 2: Photo of measuring points in vertical shaft.

$1200 \mathrm{~g}$ and using gravity to mount) are used. All accelerometers were calibrated before the field measurement. The dominant energy of targeted field is generally below $100 \mathrm{~Hz}$, and focused sensitive frequencies of vibration serviceability evaluation are in range $1 \sim 80 \mathrm{~Hz}$. Based on sampling theory (Nyquist theory), the sample frequency is set as $200 \mathrm{~Hz}$, which can satisfy with the requirements. The whole vibration test system, mainly consisted of accelerometers and the SVSA data acquisition instrument, is presented as Figure 3.

\section{Data Processing}

The data or signal, acquired by the vibration test system, needs to be preprocessed to gain the probable time domain information of relative indexes such as acceleration, velocity, and displacement. The frequency domain information of 
TABLE 1: Soil parameters of different soil layers.

\begin{tabular}{lcccccc}
\hline Soil layer no. & Soil type & Water content $(\%)$ & Thickness $(\mathrm{m})$ & Depth $(\mathrm{m})$ & Density $(\mathrm{kg} / \mathrm{m} 3)$ & Shear wave velocity $(\mathrm{m} / \mathrm{s})$ \\
\hline 1 & Filled Earth & 40.6 & 1.20 & 1.20 & 1930 & 72 \\
2 & Mucky clay & 53.6 & 3.40 & 4.60 & 1720 & 92 \\
3 & Clay & 25.1 & 2.20 & 6.80 & 1940 & 84 \\
4 & Sandy clay & 32.2 & 10.30 & 17.10 & 1950 & 115 \\
\hline
\end{tabular}

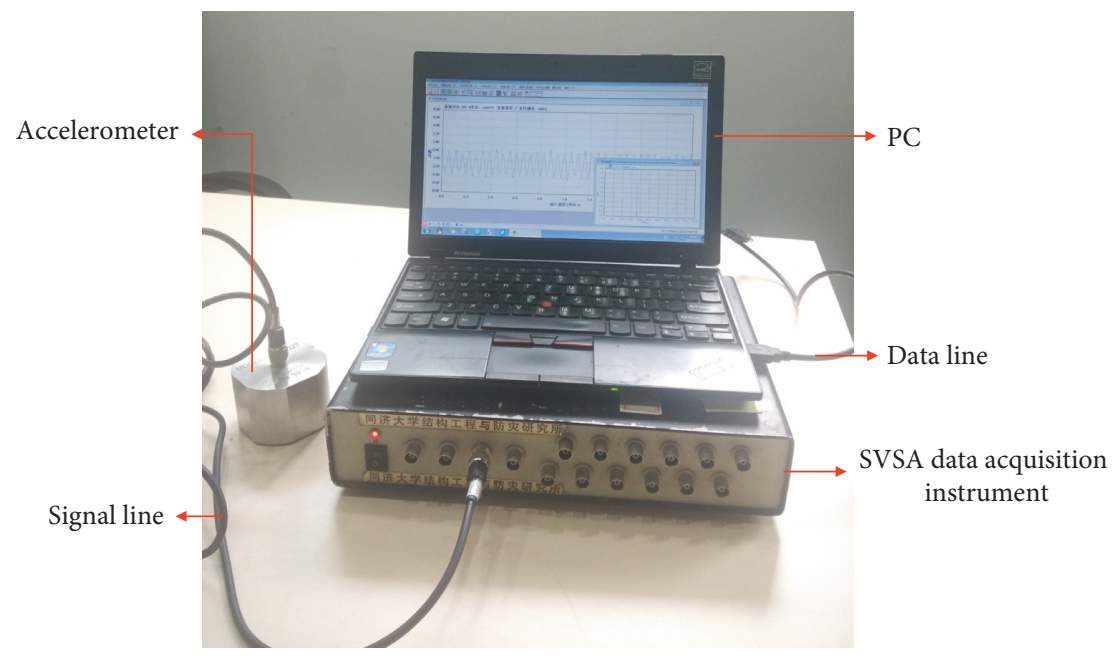

Figure 3: SVSA vibration test system.

relative indexes is obtained with an appropriate timefrequency analysis method after preprocessing the data $[25,26]$. The classic Fourier transform (FFT) method was adopted in this data processing.

3.1. Data Preprocessing. Data preprocessing is the foundation of assessing environmental vibrations correctly. The evaluation results will be inaccurate if the preprocessing steps are not appropriate or the impact of subjective human factors is introduced. According to the analysis needs of this research, the preprocessing step is displayed as Figure 4. This whole preprocessing step is developed in MATLAB software [27]. The most commonly used signal processing methods, such as data interception, low-pass filtering in the frequency domain, smoothing, removal of the trend, can be easily achieved with relative Toolbox of MATLAB software. But removing background vibration, as a key step, has to be self-programmed to achieve it. Each signal is intercepted to 40 seconds in this research. Section 3.2 and 3.3 will introduce the theory and example of removing background vibration in detail.

3.2. Theory of Removing Background Vibration. The Earth pulsates, as a phenomenon of inherent environmental vibration, is called background vibration which is dominant in low frequency. The vibration measured on field shows a tendency that components of low frequency is enhanced and high frequency is weakened as the distance between the measuring point and the vibration source (subway line) increases. Therefore, removal of background vibration from the vibration measured directly is necessary. In this section, A signifies the subway-induced vibration, $\mathrm{B}$ signifies the background vibration, and $\mathrm{A}+\mathrm{B}$ signifies the overall vibration consisting of subwayinduced vibration and background vibration. The following steps depict the process of removing the background vibration.

(i) Firstly, for the acceleration time-history $a_{\mathrm{A}+\mathrm{B}}(t)$ and $a_{\mathrm{B}}(t)$, acceleration frequency spectrum of $A_{\mathrm{A}+\mathrm{B}}(\omega)$, $A_{\mathrm{B}}(\omega)$ is gained by Equation (1), respectively. $N$ is the number of measured data. $\omega$ is the frequency.

$A(\omega)=\sum_{t=0}^{N-1} a(t) \mathrm{e}^{-i \omega t 2 \pi / N} \quad(\omega=0,1,2, \ldots, N-1)$.

(ii) Secondly, $A_{\mathrm{A}+\mathrm{B}}(\omega)$ and $A_{\mathrm{B}}(\omega)$ are substituted into Equation (2), and the phase $\theta_{\omega}$ are eliminated to get $\left|A_{\mathrm{A}+\mathrm{B}}(\omega)\right|$ and $\left|A_{\mathrm{B}}(\omega)\right|$, respectively.

$|A(\omega)|=A(\omega) \mathrm{e}^{-i \theta_{\omega}} \quad(\omega=0,1,2, \ldots, N-1)$.

(iii) Thirdly, the difference between $\left|A_{\mathrm{A}+\mathrm{B}}(\omega)\right|$ and $\left|A_{\mathrm{B}}(\omega)\right|$ is calculated to get absolute amplitude $\left|A_{\mathrm{A}}(\omega)\right|$, and then $A_{\mathrm{A}}(\omega)$ is gained through adopting phase $\theta_{\omega}$ by

$$
\begin{array}{r}
A_{\mathrm{A}}(\omega)=\left(\left|A_{\mathrm{A}+\mathrm{B}}(\omega)\right|-\left|A_{\mathrm{B}}(\omega)\right|\right) \mathrm{e}^{i \theta_{\omega}} \\
(\omega=0,1,2, \ldots, N-1) .
\end{array}
$$

(iv) Lastly, the discrete Fourier inverse transform is executed on $A_{\mathrm{A}}(\omega)$ by Equation (4). The real part is reserved, and $a_{\mathrm{A}}(t)$ of subway-induced vibration is gained finally. 


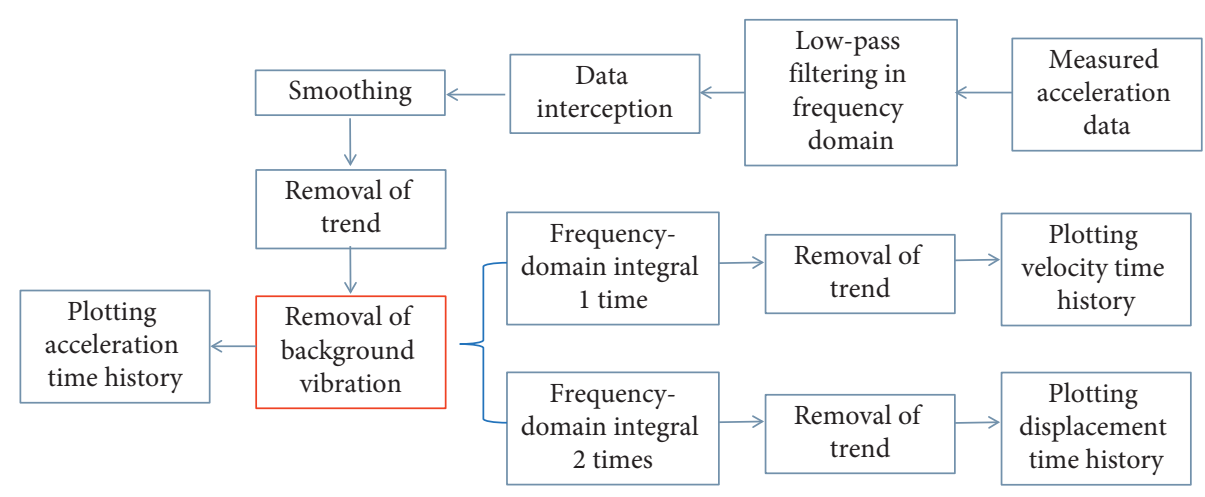

FIgURE 4: Preprocessing step of measured data.

$$
\begin{array}{r}
a_{\mathrm{A}}(t)=\frac{1}{N} \sum_{t=0}^{N-1} A_{\mathrm{A}}(\omega) a(t) e^{i \omega t 2 \pi / N} \\
(\omega=0,1,2, \ldots, N-1) .
\end{array}
$$

3.3. Example of Removing Background Vibration. The corresponding MATLAB computer program is compiled based on the above theory. Vertical vibration of measuring point W4 that is farthest from the metro line is taken as an example, and the acceleration time-history and Fourier amplitude spectrum of background vibration, overall vibration, and subway-induced vibration are presented as Figure 5.

In Figure 5, the up row is time-history of vibration and the down row is the Fourier amplitude spectrum for background, overall, and subway-induced vibration, respectively. The difference between overall and subwayinduced vibration from time domain and frequency domain is shown in Figures 5(b) and 5(c). Thus, the evaluation results may exit error if the background vibration cannot be removed from overall vibration. This conclusion is especially important for the research focused on the low-frequency component of vibrations or vibration where the measuring points are far from the source of vibration.

\section{Results of Field Vibration Measurement}

Firstly, the data of field vibration measurement were collected by the SVSA vibration test system shown in Figure 3. Then, the field data were preprocessed though the illustrative steps presented as Figure 4. The time domain information of three indexes such as acceleration, velocity, and displacement was gained. The accelerations from field measurement are real but velocity and displacement were estimated based on acceleration by frequency domain integral method. Finally, the FFT was adopted to calculate the frequency domain information based on the real acceleration data.

More than one subway-induced vibration data were collected when the field measurement was taken. The statistical results of peak value and root-mean-square (rms) value for all time-history signals of each measuring point were analysed.

\subsection{Propagation of Vibration on Free Field}

4.1.1. Time Domain Analysis. In order to illustrate the vibration on the free field, the acceleration time-histories and corresponding PSD of measuring point $\mathrm{W} 1$ in $\mathrm{Z}$ direction as the typical example as Figure 6, and the time-histories of measuring point W1 in three directions for metro 1 as the typical example was shown as Figure 7. The results of subway-induced vibration of $\mathrm{W} 1 \sim \mathrm{W} 4$ points on the free field, where the piles are not driven, are shown as Figure 8 and Table 2 . The Figure 8 not only gives the statistical results of accelerations but also the statistical results of velocities and displacements estimated from the acceleration. The number of effective acceleration data in $\mathrm{X}, \mathrm{Y}$, and $\mathrm{Z}$ direction is limited because of the weather problem and disturbance from construction machinery, etc, which are 3, 4, and 5 in three directions, respectively. Statistical results of mean values, standard deviations, and variation coefficients of peak and Rms values of subway-induced vibrations in three directions are presented in the Table 1, and only statistical results of acceleration were given due to length limitations.

It can be found from Figure 6 that there are some differences on the amplitudes of vibrations measured when different metros were passing off, but the dominant frequencies have certain regularity. This states the subwayinduced vibration featured with randomness and regularity. Figure 7 shows the general order of acceleration magnitude in three directions on the free field, and the vibration of $\mathrm{Y}$ direction is obviously dominant.

Figure 8 shows propagation trend of average vibrations on free field in three directions. The average acceleration vibrations in three directions as a whole are decaying as the distance of measuring points away from the right line increases, however there is "rebound phenomenon" in local zone; the average acceleration vibration of $\mathrm{Y}$ direction is more significant than other two directions. The reason is that the site lies at the curved segment over the metro line, and the average vibration perpendicular to metro line is predominant, which is caused by obvious lateral wheel-rail interaction. This is very different from the vibration of straight segment of metro line where the vertical vibration is predominant, but the differences of vibrations in three directions are gradually disappeared as the distances of measuring points away from the right line increase; the 

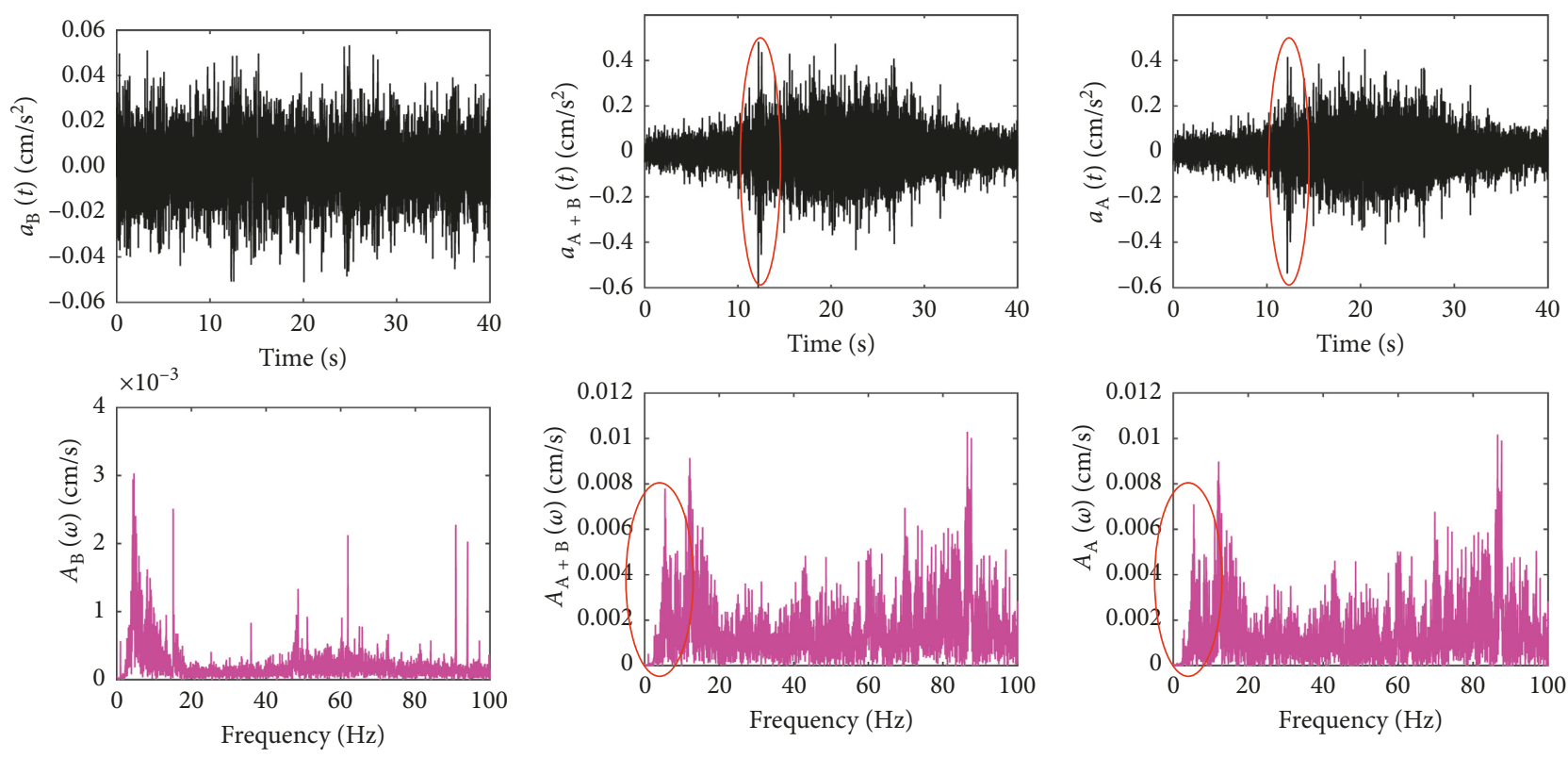

(a)

(b)

(c)

FIGURE 5: Signal comparison of background vibration, overall vibration, and subway-induced vibration. (a) Background vibration. (b) Overall vibration. (c) Subway-induced vibration.
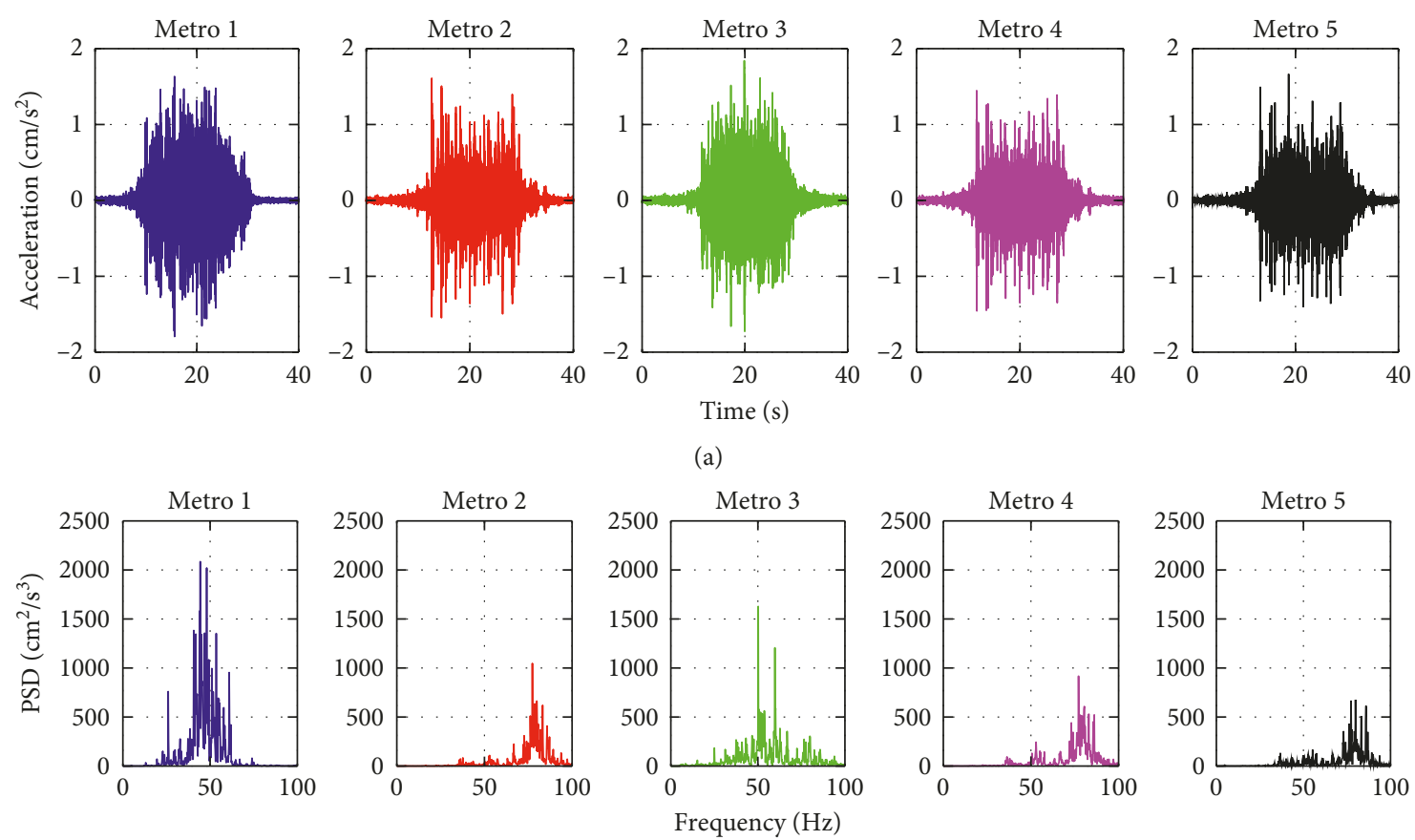

(b)

FIGURE 6: The acceleration signals of measuring point $\mathrm{W} 1$ in $\mathrm{Z}$ direction. (a) Time-history curves of acceleration. (b) PSD curves of acceleration.

average vibrations judged by the velocity and displacement estimated based on measured acceleration data also have the similar propagation trend and characteristics; the maximum of peak velocities is quite small and no more than $200 \mu \mathrm{m} / \mathrm{s}$, and the displacements are too small to measure with ordinary displacement meter, for which the maximum of peak displacements is no more than $5 \mu \mathrm{m}$. Whatever from the indexes' peak value or Rms value, the propagation trend and characteristics of vibration on the free field are same except from the value of amplitude.

Table 2 shows the detailed measured accelerations induced by subways, and same results can be gained as the 

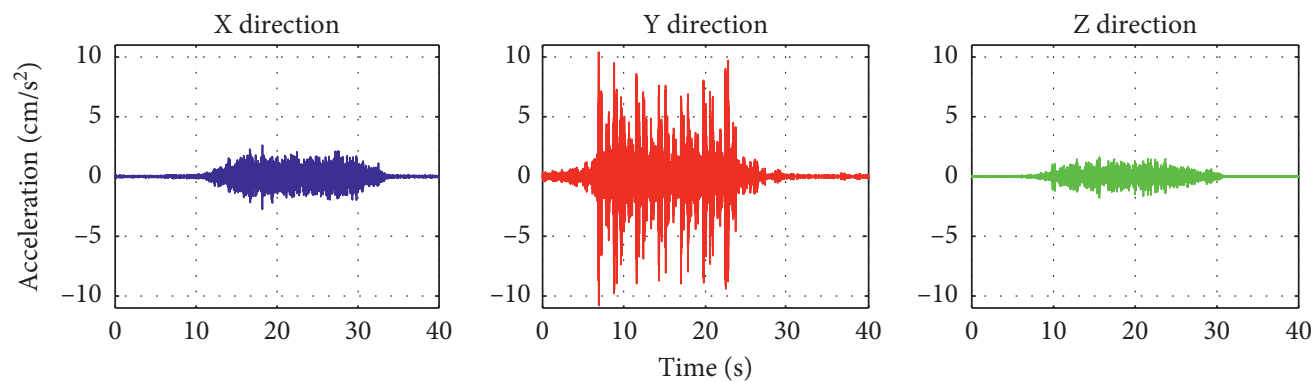

FIgURE 7: The time-history of measuring point W1 in three directions for metro 1.

Figure 8(a). Besides, standard deviations and variation coefficients of measured acceleration are varied greatly, and some of the values are large. This is because of the random characteristic of subway-induced vibration, and the randomness originates from the different loads of passing metros at different time and complexity of site soil, etc.

4.1.2. Frequency Domain Analysis. In order to investigate the propagation of vibration on free field from the view of frequency domain and energy, the average smoothed power spectral densities (PSDs) of 4 measuring points in three directions were calculated, and they were plotted in one figure as presented in Figure 9.

It is observed that the subway-induced vibration energy of point $\mathrm{W} 1$ in the frequency band which is greater than $10 \mathrm{~Hz}$ is dominant, but the vibration energy of point W4 is reversely dominant in the frequency band that is less than $10 \mathrm{~Hz}$ in three directions; the vibration energy of $\mathrm{Y}$ direction is obviously stronger than other directions, and this can also be explained by the different features with between curved and straight segment of metro line. It is also observed that the dominant frequency of measuring points $\mathrm{W} 1, \mathrm{~W} 2, \mathrm{~W} 3$, and W4 offset towards to left in X and Y direction as a whole, but there is local "rebound phenomenon," such as the dominant frequency of measuring points W3 is on the right side of W2. The dominant frequencies of four measuring points are essentially constant in $\mathrm{Z}$ direction.

\subsection{Vibration in the Vertical Shaft}

4.2.1. Time Domain Analysis. Statistical acceleration timehistory results of subway-induced vibration of S1 and S2 points are shown in Figure 10 due to length limitations. Also, only 5 groups' effective data were collected in three directions because of weather problem and disturbance from construction machinery, etc. The data of S1 and S2 (6 channels: S1-x, S1-y, S1-z and S2-x, S2-y, S2-z) were measured simultaneously when metro passed.

Figure 10 shows the comparison of average vibrations between point S1 represented the pile top and point S2 represented the site soil near pile in three directions. It is observed that the acceleration of pile top is larger than site soil in three directions no matter whatever from the peak values or the Rms values, and this signifies that vibration is more easily propagated along the pile than the soil; for the vibration of pile top, the order of amplitude is $\mathrm{Z}>\mathrm{Y}>\mathrm{X}$, but as for the site soil, the order is $\mathrm{Y}>\mathrm{Z}>\mathrm{X}$, which can be seen easily through the peak values and $R m s$ values. The order $Z>$ $\mathrm{Y}>\mathrm{X}$ illustrates that the vertical vibration of top of pile is more predominant than lateral vibration for propagating along the pile at the curved segment of metro line, but the order $\mathrm{Y}>\mathrm{Z}>\mathrm{X}$ of site soil is similar to the free field.

4.2.2. Frequency Domain Analysis. To investigate the vibration differences in the vertical shaft from the view of frequency and energy, the average smoothed power spectral densities (PSDs) of measuring points S1 and S2 in three directions were calculated and fitted, respectively. The smoothed average acceleration PSDs of measuring points S1 and S2 were plotted in one figure as shown in Figure 11.

Figure 10 gives the comparison between smoothed PSDs of S1 and S2 in three directions. It is observed that the subwayinduced vibration energy of S1 is not always stronger than S2 and reversed in some frequency bands for different directions. As for the $\mathrm{X}$ direction, the vibration energy of S1 is stronger than S2 when the frequency is between $37 \mathrm{~Hz}$ and $70 \mathrm{~Hz}$, and the situation turned over when frequency is less than $37 \mathrm{~Hz}$ and more than $70 \mathrm{~Hz}$; for the $\mathrm{Y}$ direction, the vibration energy of S1 is stronger than S2 almost in all frequency bands except for $65 \sim 77 \mathrm{~Hz}$; for the $\mathrm{Z}$ direction, $48 \mathrm{~Hz}$ is the frequency of turning point, and the vibration energy of $S 1$ is stronger than S2 when the frequency is more than $48 \mathrm{~Hz}$, and vibration energy of S1 becomes smaller than S2 when the frequency is less than $48 \mathrm{~Hz}$.

\section{Subway-Induced Vibration of the Building to Be Built}

The building to be built is rightly over the zone of vertical shaft, and the longitudinal direction of building is parallel with direction of perpendicular to metro line (Y direction).

5.1. The Information of the Building and Structure Model. The building will be used as the serviced apartment that includes three stories underground and ten stories above the ground. The function of three stories underground will be as parking lots and supermarkets, and ten stories above the ground will become luxury apartments. The building plan of the typical story (6th story of the building) is shown as Figure 12. 

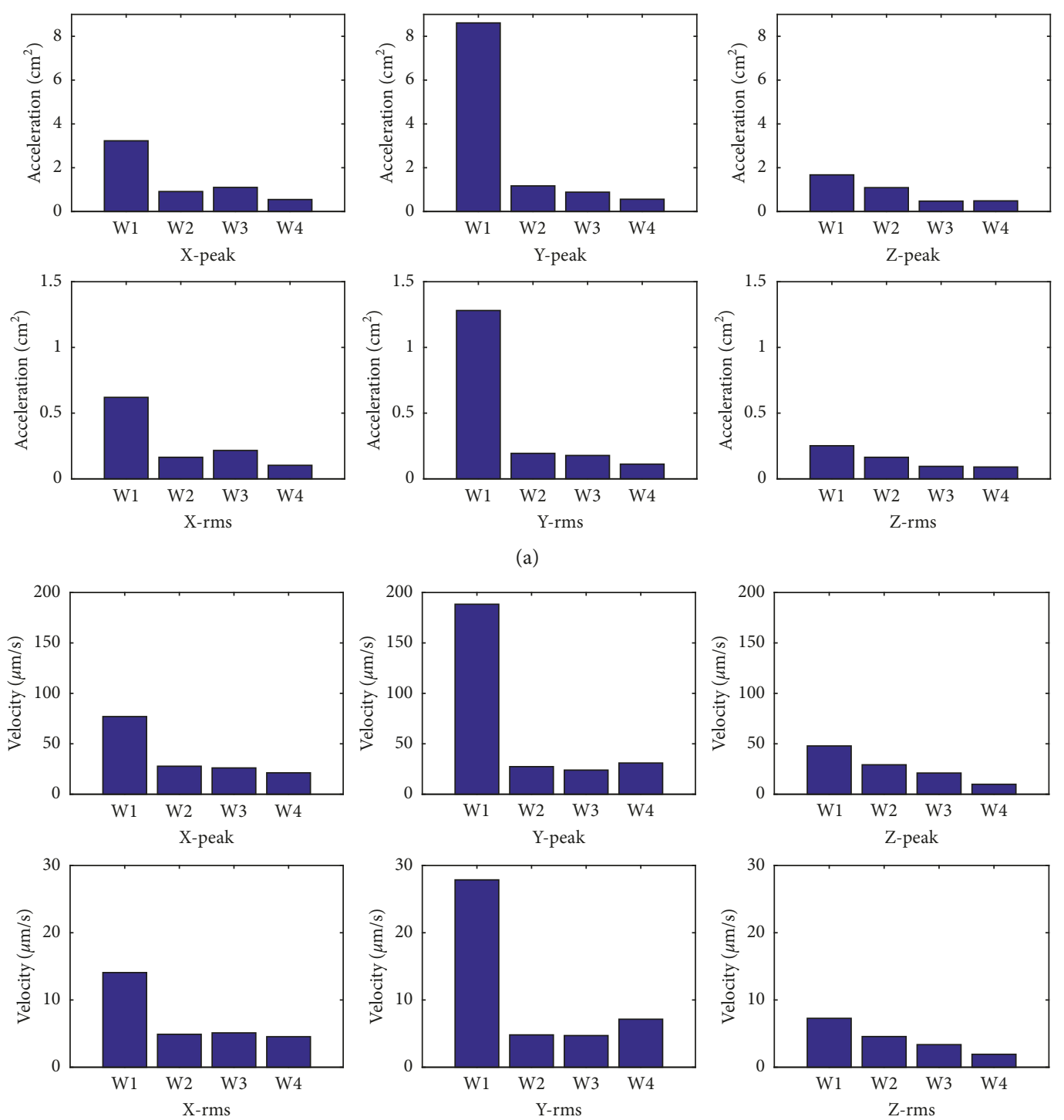

(b)
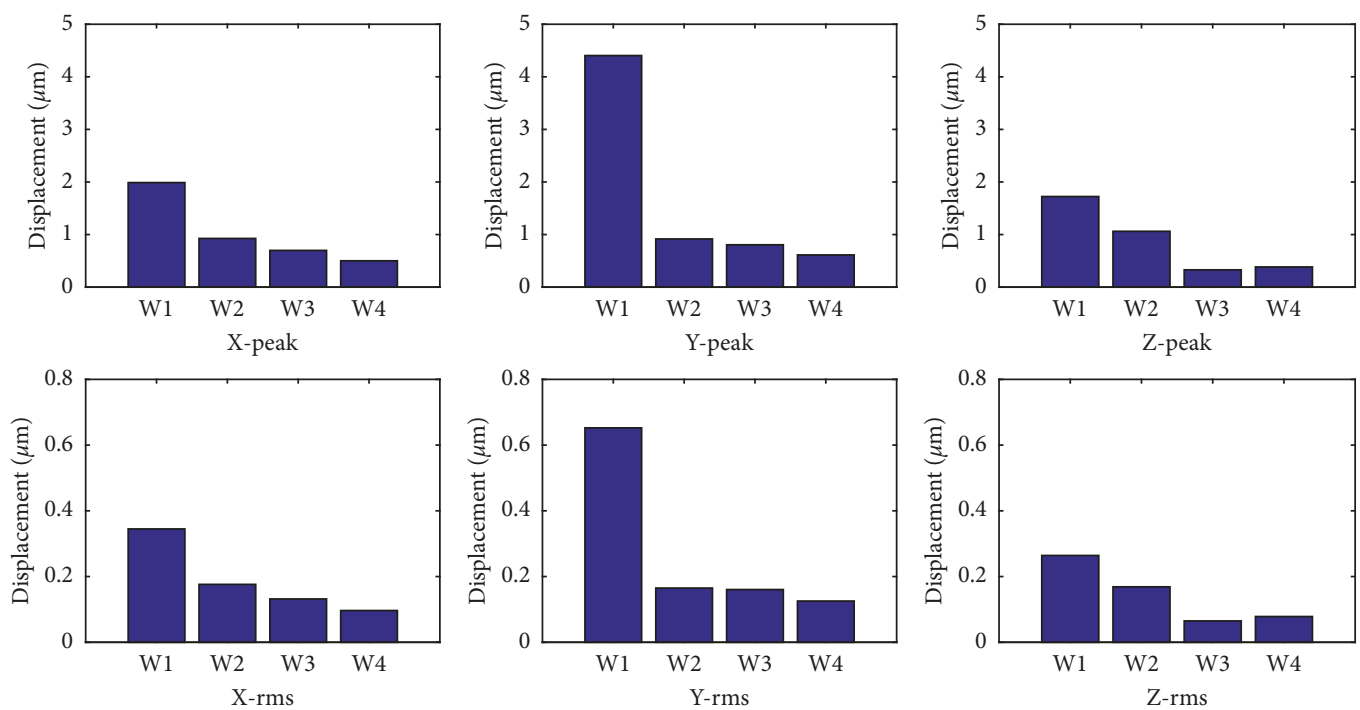

(c)

Figure 8: The average value of 3 indexes induced by subways on free field. (a) Acceleration. (b) Velocity. (c) Displacement. 
TABLE 2: Mean values, standard deviations, and variation coefficients of peak and Rms values of accelerations induced by metros in three directions.

\begin{tabular}{|c|c|c|c|c|c|c|c|c|c|}
\hline \multirow{3}{*}{\multicolumn{2}{|c|}{$\begin{array}{l}\text { Index } \\
\text { Measurement point }\end{array}$}} & \multicolumn{8}{|c|}{ Acceleration $\left(\mathrm{cm} / \mathrm{s}^{2}\right)$} \\
\hline & & \multicolumn{4}{|c|}{ Peak } & \multicolumn{4}{|c|}{ Rms } \\
\hline & & W1 & W2 & W3 & W4 & W1 & W2 & W3 & W4 \\
\hline \multicolumn{2}{|c|}{ Distance to metro line $(\mathrm{m})$} & 5 & 17 & 26 & 35 & 5 & 17 & 26 & 35 \\
\hline \multirow{6}{*}{$\mathrm{X}$ direction } & Metro 1 & 2.749 & 0.981 & 0.605 & 0.771 & 0.471 & 0.183 & 0.107 & 0.143 \\
\hline & Metro 2 & 3.525 & 0.986 & 1.720 & 0.453 & 0.739 & 0.164 & 0.354 & 0.083 \\
\hline & Metro 3 & 3.413 & 0.771 & 0.978 & 0.421 & 0.650 & 0.146 & 0.187 & 0.084 \\
\hline & Mean values & 3.229 & 0.913 & 1.101 & 0.548 & 0.620 & 0.164 & 0.216 & 0.103 \\
\hline & Standard deviations & 0.420 & 0.123 & 0.567 & 0.194 & 0.136 & 0.018 & 0.126 & 0.034 \\
\hline & Variation coefficients & 0.130 & 0.135 & 0.515 & 0.353 & 0.220 & 0.112 & 0.582 & 0.328 \\
\hline \multirow{7}{*}{ Y direction } & Metro 1 & 10.798 & 1.518 & 0.800 & 0.363 & 1.504 & 0.221 & 0.133 & 0.079 \\
\hline & Metro 2 & 7.366 & 1.150 & 1.237 & 0.746 & 1.323 & 0.223 & 0.249 & 0.142 \\
\hline & Metro 3 & 3.524 & 0.596 & 0.940 & 0.739 & 0.550 & 0.102 & 0.197 & 0.153 \\
\hline & Metro 4 & 12.754 & 1.420 & 0.557 & 0.395 & 1.744 & 0.230 & 0.132 & 0.072 \\
\hline & Mean values & 8.611 & 1.171 & 0.884 & 0.561 & 1.281 & 0.194 & 0.178 & 0.112 \\
\hline & Standard deviations & 4.057 & 0.414 & 0.284 & 0.210 & 0.516 & 0.062 & 0.056 & 0.042 \\
\hline & Variation coefficients & 0.471 & 0.353 & 0.321 & 0.374 & 0.403 & 0.318 & 0.317 & 0.374 \\
\hline \multirow{8}{*}{$\mathrm{Z}$ direction } & Metro 1 & 1.794 & 0.893 & 0.402 & 0.265 & 0.309 & 0.156 & 0.077 & 0.054 \\
\hline & Metro 2 & 1.610 & 1.140 & 0.463 & 0.538 & 0.226 & 0.160 & 0.097 & 0.100 \\
\hline & Metro 3 & 1.841 & 1.309 & 0.532 & 0.609 & 0.275 & 0.179 & 0.099 & 0.092 \\
\hline & Metro 4 & 1.457 & 0.996 & 0.448 & 0.508 & 0.226 & 0.160 & 0.100 & 0.106 \\
\hline & Metro 5 & 1.666 & 1.118 & 0.530 & 0.508 & 0.226 & 0.166 & 0.102 & 0.099 \\
\hline & Mean values & 1.674 & 1.091 & 0.475 & 0.486 & 0.252 & 0.164 & 0.095 & 0.090 \\
\hline & Standard deviations & 0.153 & 0.157 & 0.056 & 0.130 & 0.038 & 0.009 & 0.010 & 0.021 \\
\hline & Variation coefficients & 0.091 & 0.144 & 0.118 & 0.268 & 0.151 & 0.054 & 0.107 & 0.232 \\
\hline
\end{tabular}

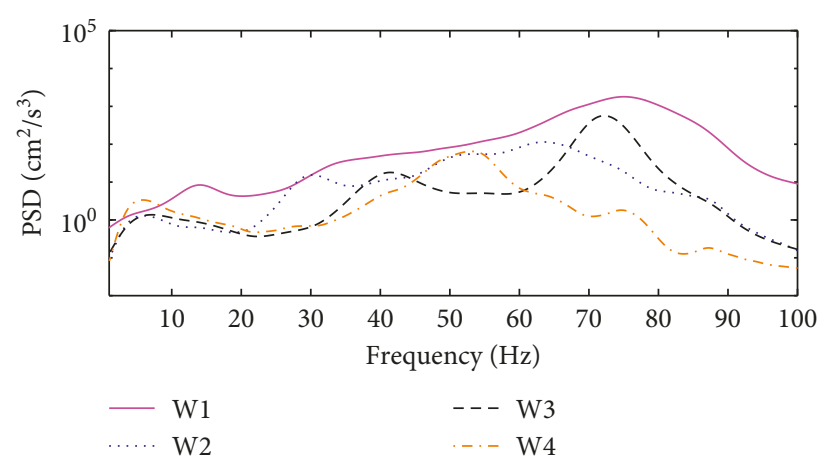

(a)

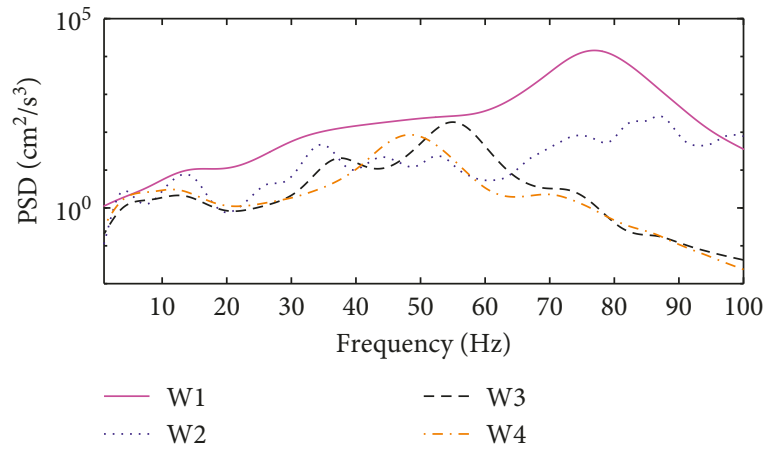

(b)

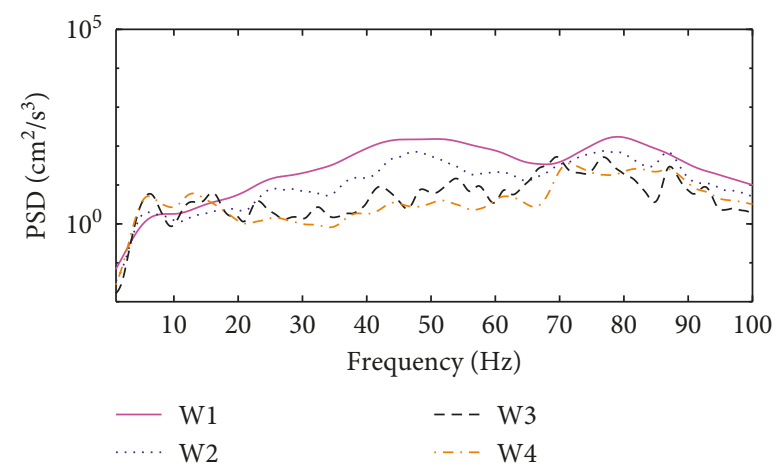

(c)

FIgURE 9: The smoothed average acceleration PSDs of subway-induced vibration on free field. (a) X direction. (b) Y direction. (c) Z direction. 


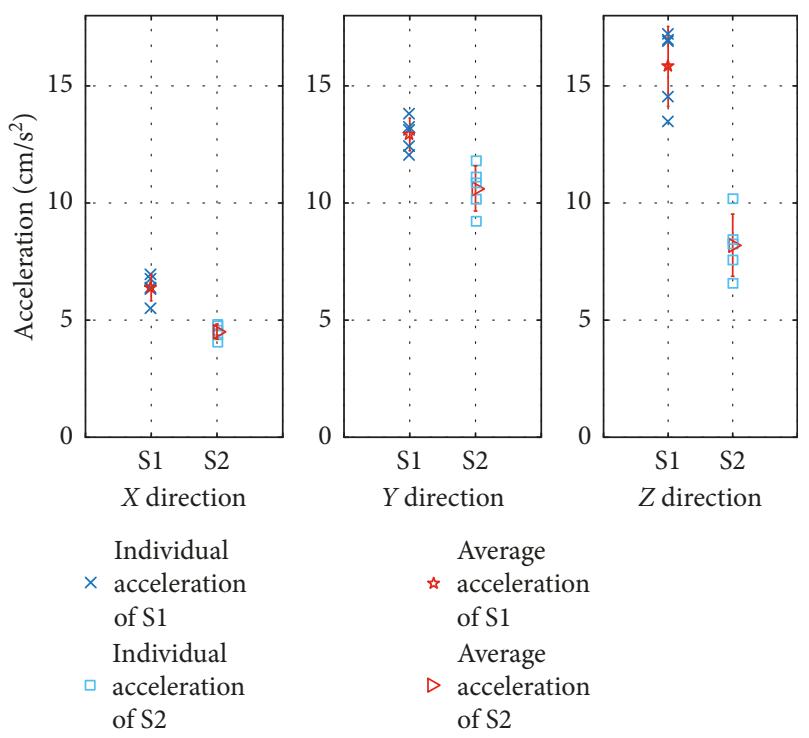

(a)
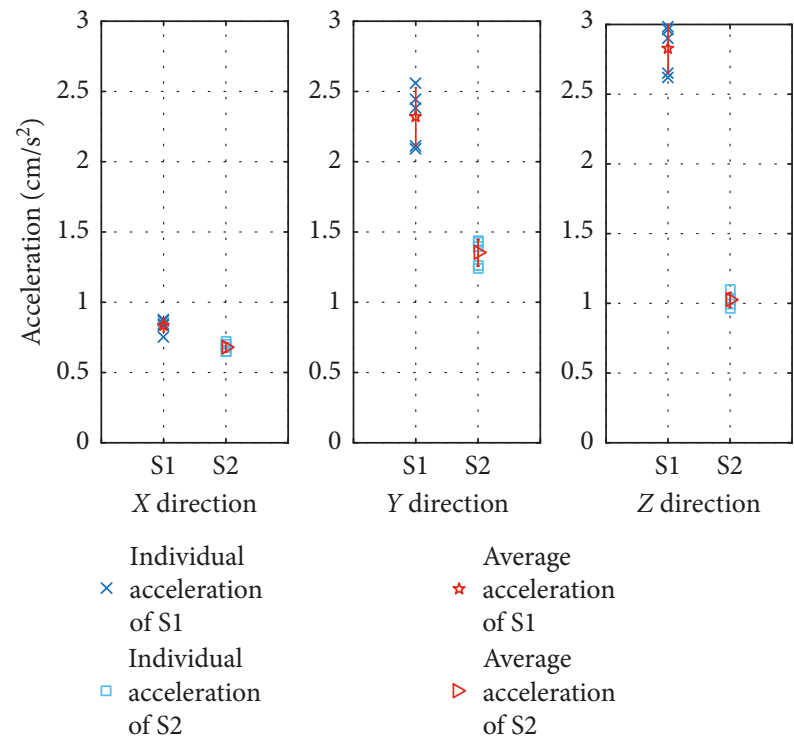

Average

* acceleration of S1

Average

$\triangle$ acceleration of S2

(b)

Figure 10: The average vibration acceleration of measuring points S1 and S2 induced by subway. (a) Peak values. (b) Rms values.

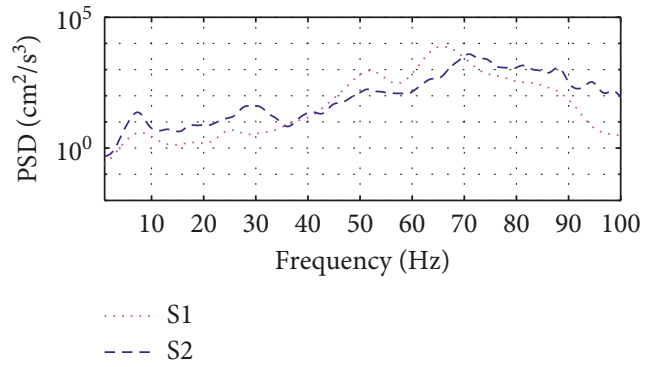

(a)

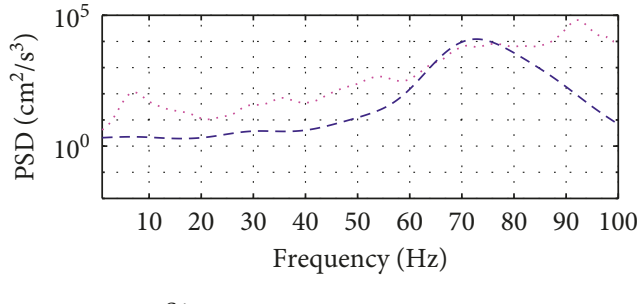

…...S1

$---\mathrm{S} 2$

(b)

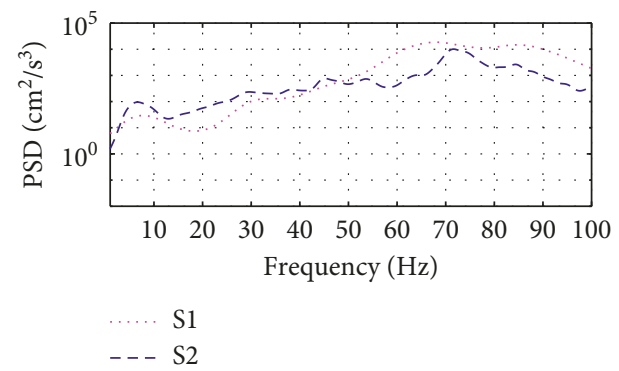

(c)

FIGURE 11: The smoothed average acceleration PSD of measured points S1 and S2 induced by subway. (a) X direction. (b) Y direction. (c) Z direction.

The structure of underground part is reinforced concrete shear wall, and the above part is reinforced concrete frame. The type of foundation of the building is the pile foundation. For the underground part, typical column is circular for which diameter is $1000 \mathrm{~mm}$, typical beam is rectangle of which size is $800 \mathrm{~mm} * 400 \mathrm{~mm}$, the thickness of shear wall is among 200-900 mm, and the thickness of slab is $600 \mathrm{~mm}$; for the part above the ground, typical column is rectangle for which size is $600 \mathrm{~mm} * 600 \mathrm{~mm}$, typical beam is rectangle for which size is $(600 \mathrm{~mm} \sim 700 \mathrm{~mm}) * 300 \mathrm{~mm}$, and the thickness of slab is $100 \mathrm{~mm}$.

The structure model of the building was built by SAP2000. The mass in the model is considered as combination of $1.0 *$ dead load and $0.5 *$ live load, the stiffness of all members is set as the elastic stiffness, the element meshing obeys the $1 / 8$ wavelength principal, and the damping is considered to follow Rayleigh damping approach. About the damping, the 5.4 part will have a detail discussion. In the 


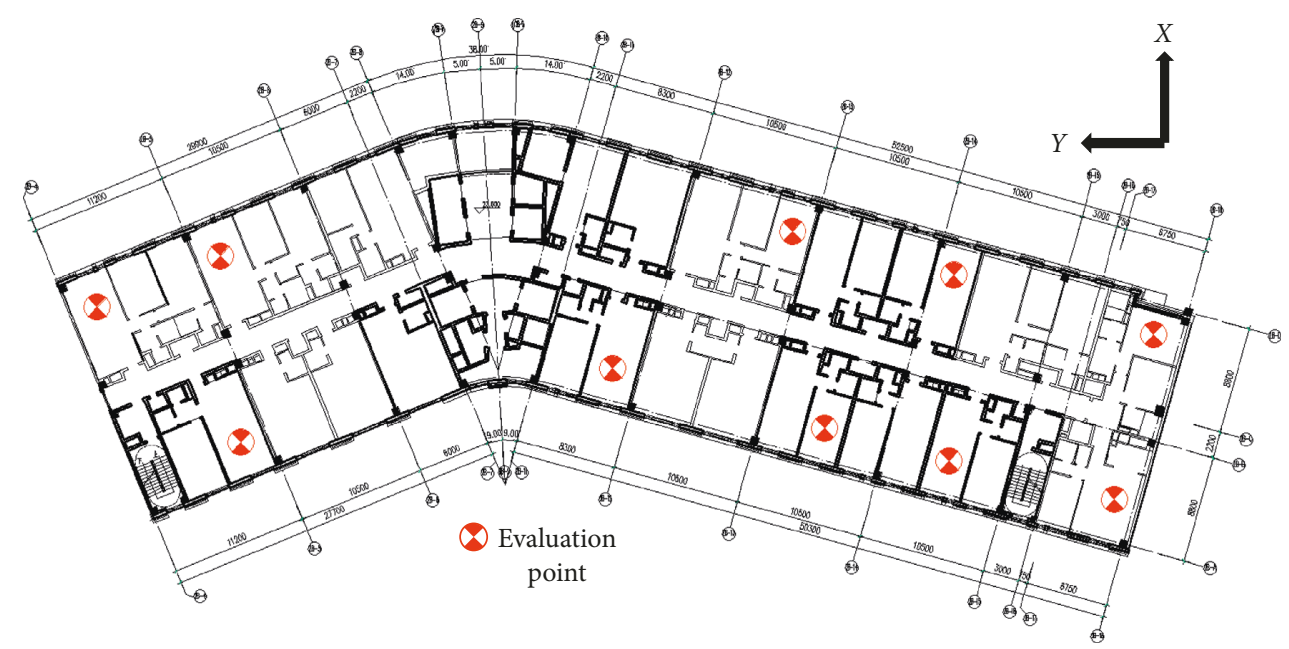

FIGURE 12: The plan view of the evaluation points at typical story ( $6^{\text {th }}$ story).

model, the beams and columns are simulated by line element and the walls and slabs by elastic shell element. The linear modal time-history analysis method was adopted as calculation method, and the first 200 order modes were taken. The analysed SAP200 model is presented as Figure 13.

5.2. The Excitation Was Inputted into the Model. In this research, since it is assumed that the presence of the building does not affect the vibration generation source [20], the vibration measured is used as excitation source to the structure. The basement, which is the negative third floor for parking cars that elevation is $-15.00 \mathrm{~m}$, is assumed to have infinite stiffness and hereby the SSI effect is ignored. Meanwhile, the measured acceleration time-history response of point $\mathrm{S} 1$ is directly as the input of the building to simulate the vibration induced by passage of metro. The excitation to be inputted into the basement of structure was randomly selected from measured accelerations time-history of point S1 in the vertical shaft. The detailed time and domain information of the excitation are presented in Figure 14. The basement of building is pile foundation and simplified as rigid body connected with the ground in this analysis. In the SAP2000 model, the selected time-history of accelerations in three directions was inputted into the base of building directly.

The directions input to structure are in accord with the arrow direction in Figure 11, where $\mathrm{X}$ signifies the short direction and $\mathrm{Y}$ signifies long direction of the building.

As is shown in Figure 14, the amplitude of excitation in $\mathrm{Z}$ direction is maximum, followed by $\mathrm{Y}$ direction, and $\mathrm{X}$ direction is minimum from the perspective of time domain. From the perspective of frequency domain, the energy of excitation in $\mathrm{X}$ direction mainly distributes among $60 \sim 70 \mathrm{~Hz}, \mathrm{Y}$ direction mainly distributes around $90 \mathrm{~Hz}$, and $\mathrm{Z}$ direction mainly distributes among $60 \sim 90 \mathrm{~Hz}$ which is wider than other two directions.

5.3. The Evaluation Indicators. The vibration level is the usual indicator when evaluating all kinds of vibrations. Here, two evaluation indicators are adopted, which are acceleration vibration level $L_{\mathrm{a}}$ and velocity vibration level $L_{\mathrm{v}}$.

According to International Standard for Human Response to Whole-body Vibration (ISO2631) [28, 29], the acceleration level is defined as follows:

$$
L_{\mathrm{a}}=20 \log _{10} \frac{a_{\mathrm{rms}}}{a_{0}},
$$

where $a_{0}$ is the referenced acceleration; its value is $1 \times 10^{-6} \mathrm{~m} / \mathrm{s}^{2}$ based on ISO2631. $a_{\mathrm{rms}}$ is the root-meansquare value of acceleration with frequency weighting.

The velocity level is an indicator that is mainly recommended by Federal Transit Administration (FTA) criteria [30]. The velocity level is defined as follows:

$$
L_{\mathrm{v}}=20 \log _{10} \frac{v_{\mathrm{rms}}}{v_{0}},
$$

where $v_{0}$ is the referenced acceleration; its value is $2.54 \times 10^{-8} \mathrm{~m} / \mathrm{s} . \quad v_{\text {rms }}$ is the root-mean-square value of acceleration but with no frequency weighting.

5.4. The Influence of Damping Ratio on the Vibration Level. The Rayleigh damping approach was followed in this research, and the damping matrix $[C]$ of the system can be expressed as follows:

$$
[C]=\alpha[M]+\beta[K],
$$

where $[M]$ and $[K]$ are mass matrix and stiffness matrix, respectively. The $\alpha$ and $\beta$ are combination coefficients of mass matrix and stiffness matrix, respectively, and they can be determined by

$$
\left(\begin{array}{l}
\alpha \\
\beta
\end{array}\right)=\frac{2 \xi}{\omega_{1}+\omega_{2}}\left(\begin{array}{c}
\omega_{1} \omega_{2} \\
1
\end{array}\right),
$$

where $\omega_{1}$ and $\omega_{2}$ are two frequencies of the system and $\xi$ as the key parameter is the damping ratio of the system.

The value of $\omega_{1}$ always equals the fundamental frequency of system, and $\omega_{2}$ is generally selected from high frequencies 


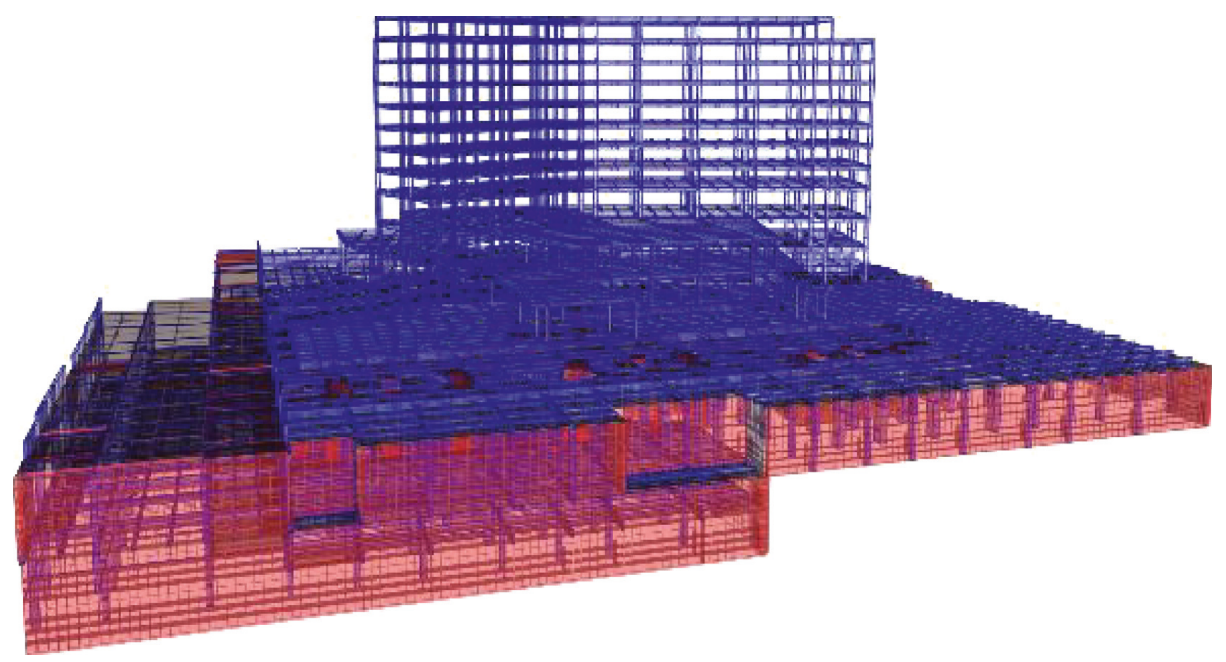

Figure 13: The SAP2000 model of the building.
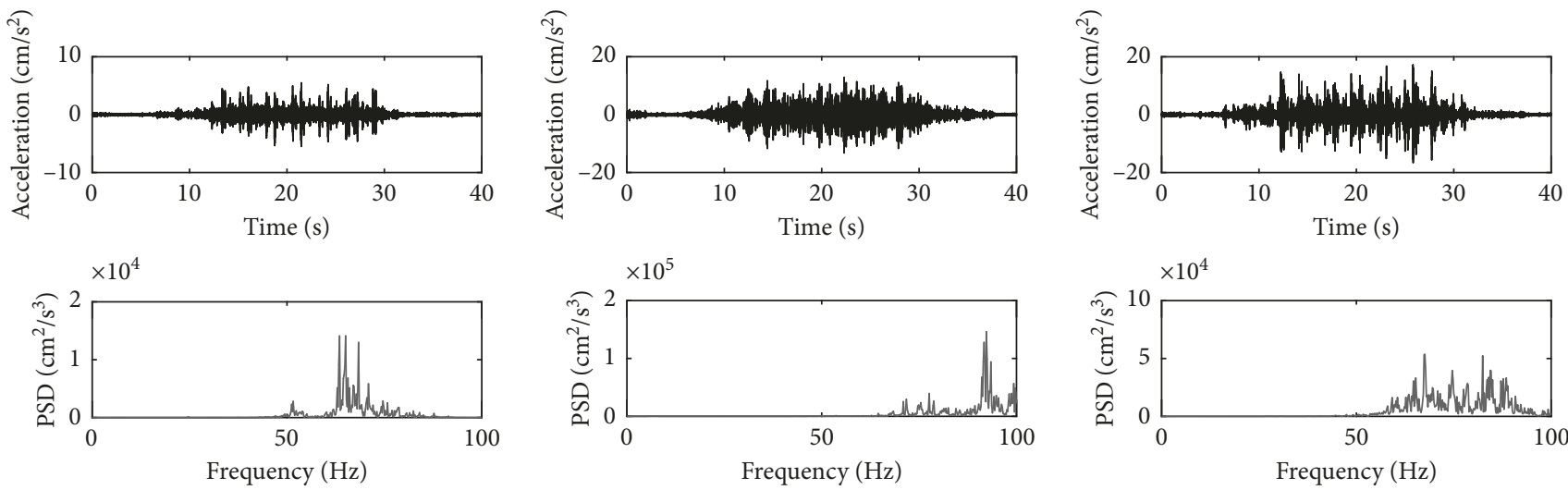

(a)

(b)

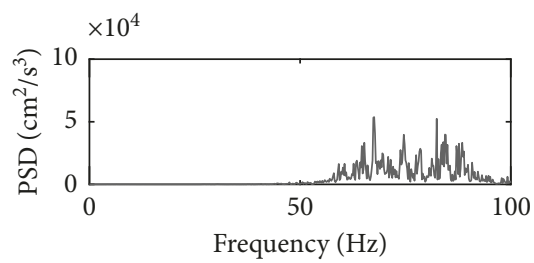

(c)

FIgURE 14: The excitations to be inputted. (a) X direction. (b) Y direction. (c) Z direction.

that have significant effect on dynamic response. In fact, dynamic response of structure is not only depending on the dynamic characteristics of structure, but also the characteristics of frequency spectrum of vibration load. Based on the report of Idriss [31] on improving of above traditional method, $\omega_{1}$ and $\omega_{2}$ are set as $10 \mathrm{~Hz}$ and $70 \mathrm{~Hz}$ here.

As the most important parameter in the Rayleigh damping approach, the damping ratio $\xi$ varies in different analysis, but it is in proportional to dynamic response of structure. For example, when the seismic analysis is carried out, it often set as $2 \%$ for steel structure but $5 \%$ for reinforced concrete structure. When the issues of slab serviceability are focused, the $\xi$ often takes $2 \%$ for reinforced concrete structure and less than $2 \%$ for steel structure. In here, the damping ratios equating to $1 \%, 2 \%, 3 \%, 4 \%$, and $5 \%$, respectively, were taken to study the influence of damping ratio on the vibration level of the structure. The influence of damping ratio on acceleration level $L_{\mathrm{a}}$ and velocity level $L_{\mathrm{v}}$ in the frequency domain is pictured as Figures 15 and 16, respectively.

The average one-third octave spectrum of the acceleration level of typical story in three directions for different damping ratios is shown in Figure 15. It is obvious that the acceleration level increases as the damping ratio reduces among almost frequency range in all three directions. However, the shapes of one-third octave spectra are various for different directions. For example, the peak values appear around $5 \mathrm{~Hz}$ and the acceleration level is almost below $30 \mathrm{~dB}$ when frequency is beyond $10 \mathrm{~Hz}$ for the $\mathrm{X}$ and $\mathrm{Y}$ directions. But for $\mathrm{Z}$ direction, the peak values appear around $6.3 \mathrm{~Hz}$ and the acceleration levels in all frequency range are above $30 \mathrm{~dB}$. These are because that low-order modes of whole structure, which mainly represent lateral modes, make remarkable contribution to the lateral vibration response, while the high-order mode of whole structure and local modes of slabs contribute to the vertical response much.

Also, the average one-third octave spectra of the velocity level of typical story in three directions for different damping ratio are shown in Figure 17. It can be found that there are almost no differences except the magnitude between average velocity level and acceleration level among one-third octave frequency band. Therefore, the same conclusions can be derived as same as Figure 14. 


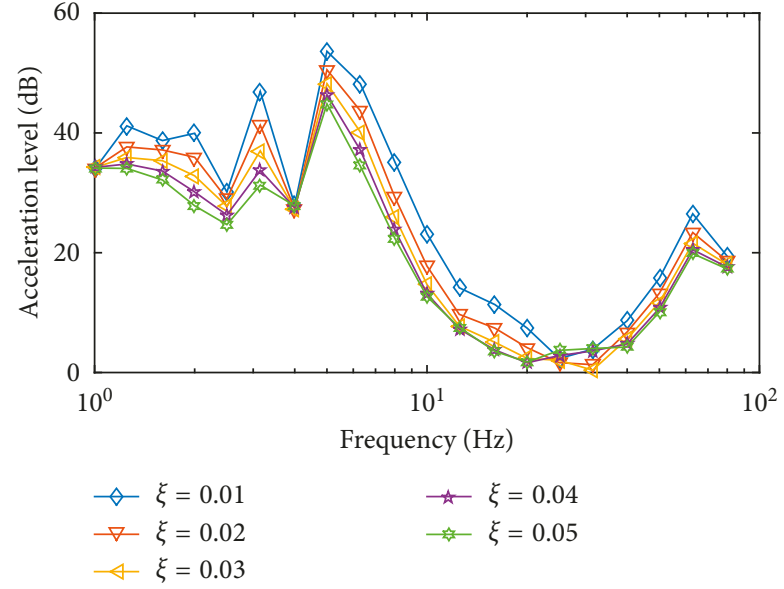

(a)

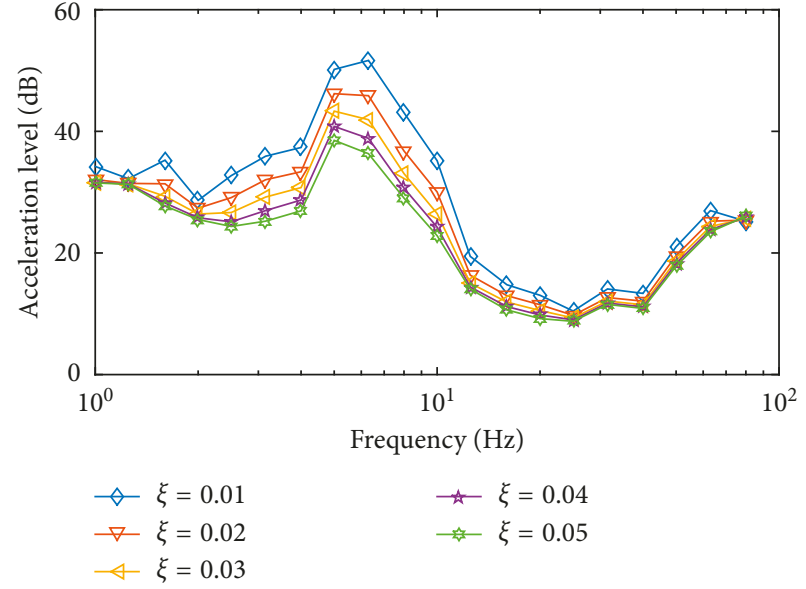

(b)

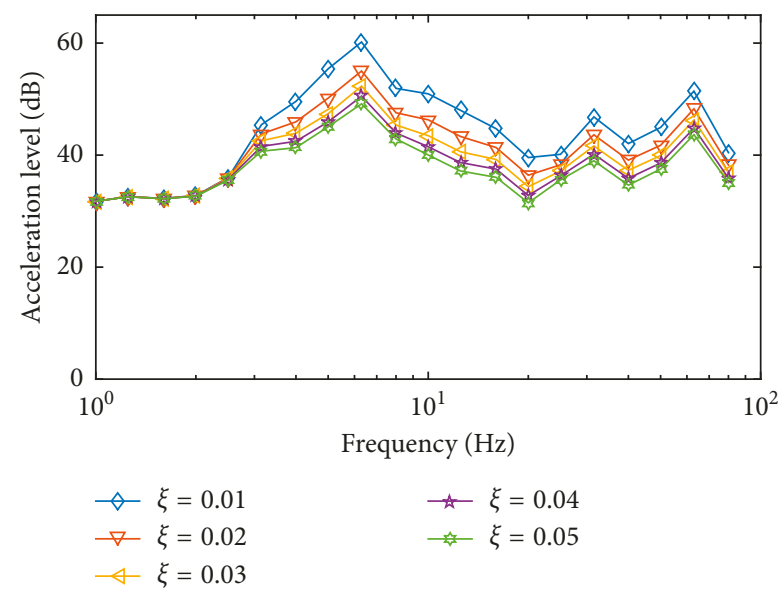

(c)

FIGURE 15: The average one-third octave spectra of the acceleration level of typical story ( $6^{\text {th }}$ story) for different damping ratio. (a) X direction. (b) Y direction. (c) Z direction.

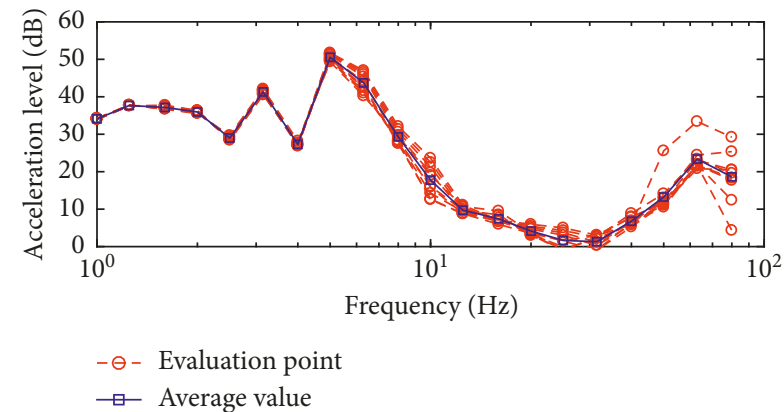

(a)

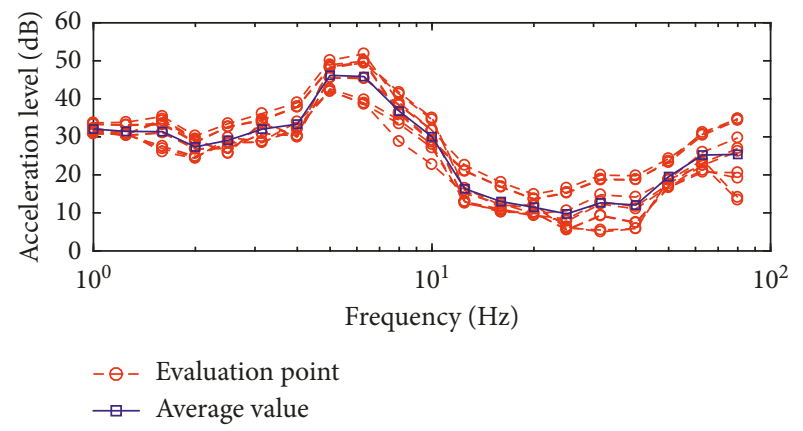

(b)

FIgURE 16: Continued. 


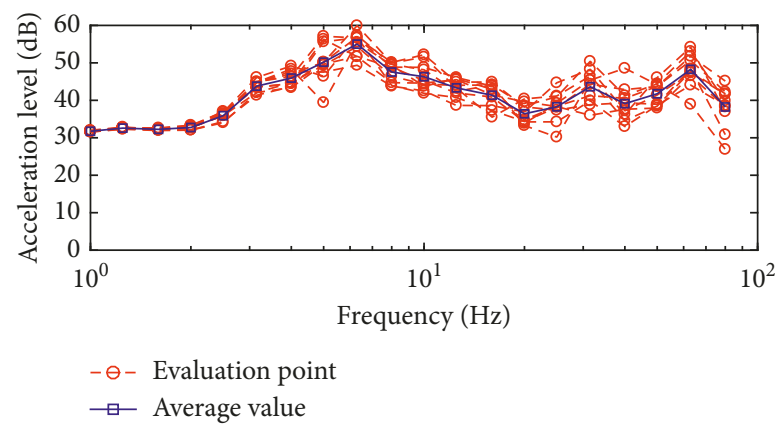

(c)

FIGURE 16: The one-third octave and average spectra of the accelerations of each evaluation point at typical story $\left(6^{\text {th }}\right.$ story, damping ratio $=$ 0.02). (a) X direction. (b) Y direction. (c) Z direction.

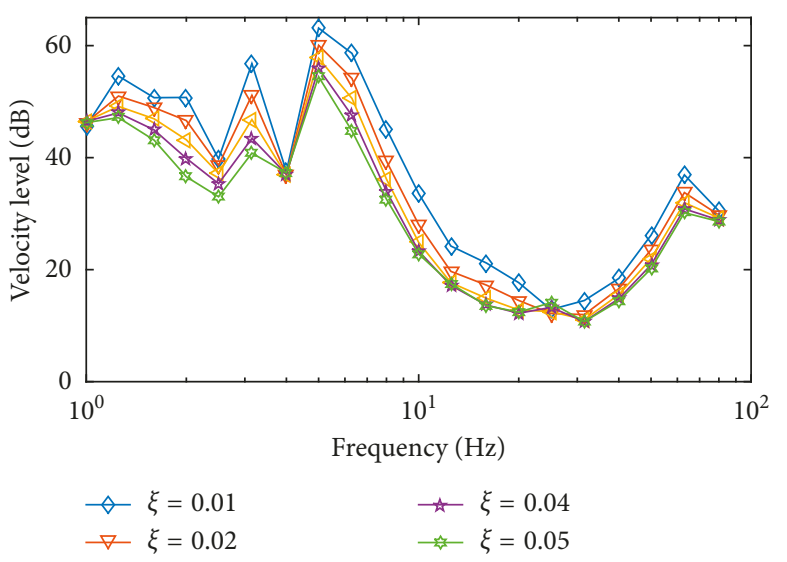

(a)

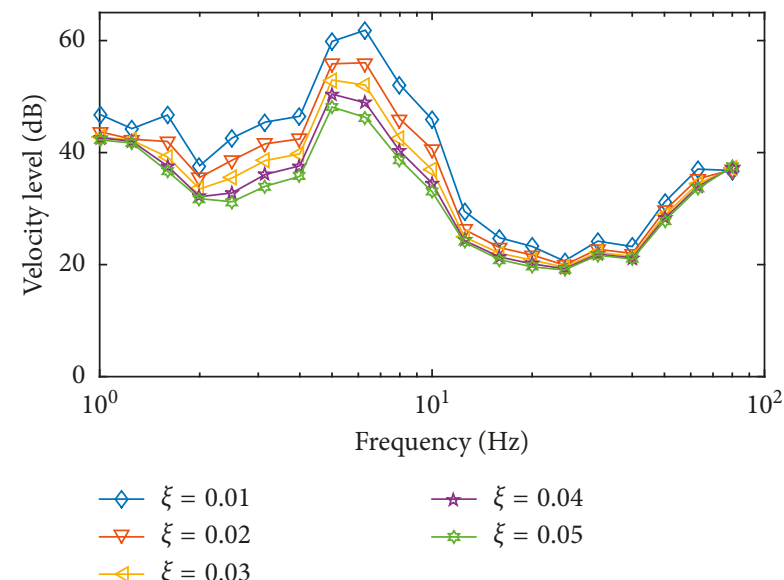

(b)

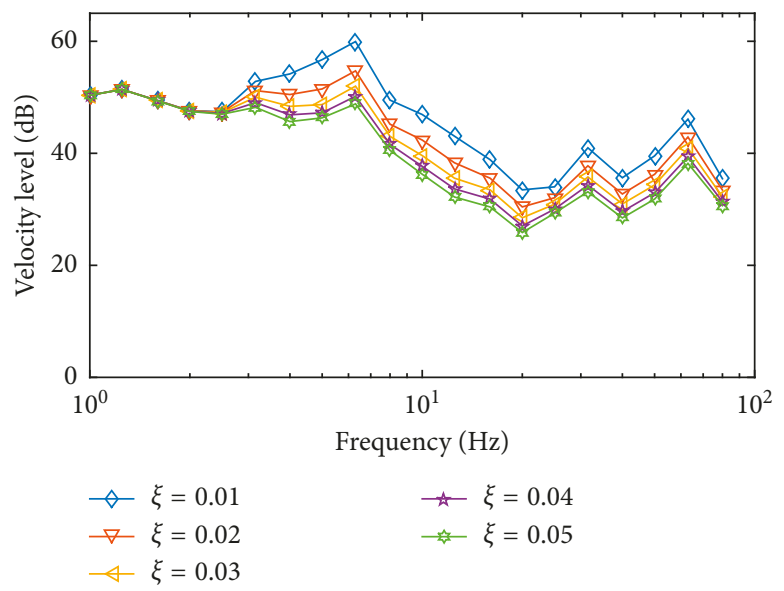

(c)

FIGURE 17: The average one-third octave spectra of the velocity level of typical story $\left(6^{\text {th }}\right.$ story) for different damping ratio. (a) X direction. (b) $\mathrm{Y}$ direction. (c) $\mathrm{Z}$ direction.

5.5. The Distribution of Acceleration Level along the HeightWise. In order to discern the distribution of acceleration indicators along the high-wise, one-third octave spectra of accelerations of each evaluation point and their average spectra were gained and pictured as Figure 16. Then, the distribution of average maximum frequency acceleration level $L_{\mathrm{a} \text {, max }}$ along the high-wise was calculated and depicted as Figure 18. Here, only the case of damping ratio equal to $2 \%$ is showed due to limited space.

It is observed from the curves of "average values" in Figure 16 that the spectral shapes are similar in $\mathrm{X}$ and $\mathrm{Y}$ direction, and the peak values all appear at $5 \mathrm{~Hz}$. But for $\mathrm{Z}$ 


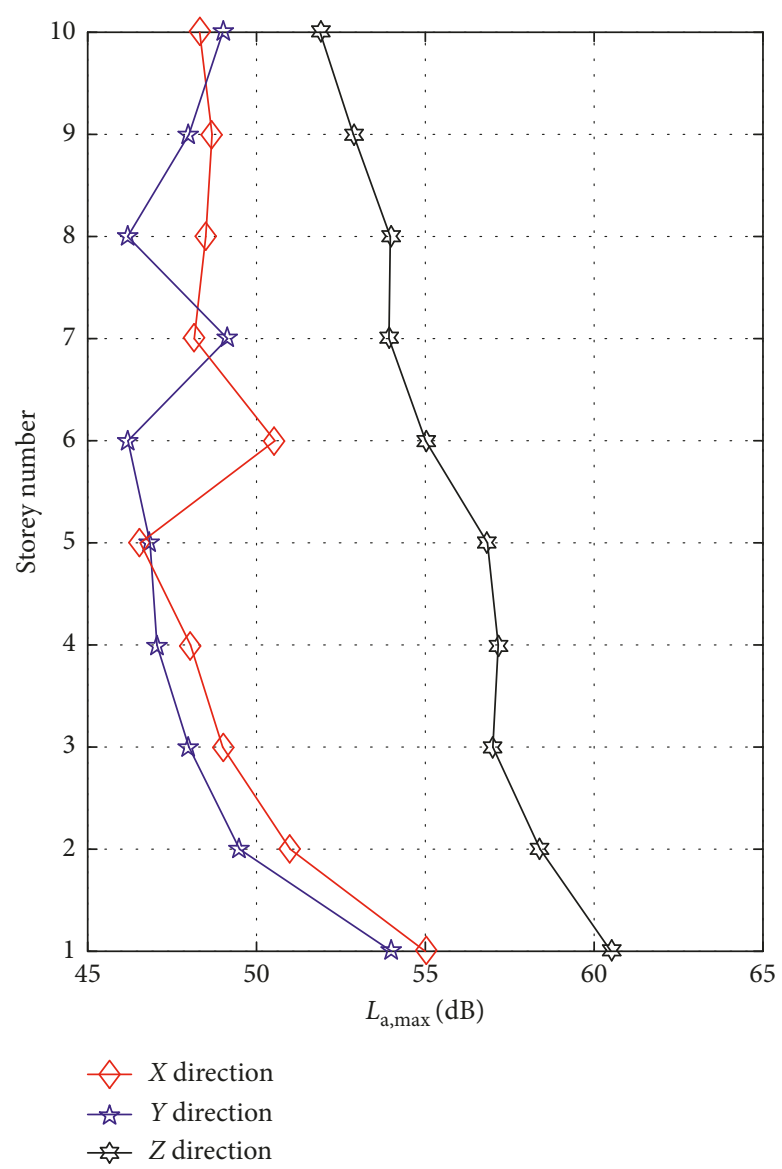

FIGURE 18: The distribution of maximum frequency acceleration level along the high-wise (damping ratio $=0.02$ ).

direction, the spectral shape is different from another two directions, and the peak value appears at $6.3 \mathrm{~Hz}$. Based on the curves of "evaluation points" of Figure 16, the spectral shapes of different evaluation points basically have uniform trend among the whole frequency range in both $\mathrm{X}$ and $\mathrm{Y}$ directions, especially in $\mathrm{X}$ direction. But for $\mathrm{Z}$ direction, there exists different situation that the spectral shapes of different evaluation points are not as uniform as X direction. The above occurrence can be explained by the fact that the stiffness in the lateral direction hardly changes for each evaluation point, but in the same story, the stiffness in the vertical direction is variable.

The comparison of the distribution of maximum frequency acceleration level $L_{\mathrm{a}, \max }$ along the high-wise in three directions is pictured as Figure 18. The $L_{\mathrm{a}, \max }$, for $\mathrm{X}$ directions, decreases as the story number increases between $1^{\text {st }}$ and $5^{\text {th }}$ story and then increases zigzagged slightly above $5^{\text {th }}$ story. The distribution of $L_{\mathrm{a} \text {, } \max }$ in $\mathrm{Y}$ direction is similar to $\mathrm{X}$ direction. For $\mathrm{Z}$ direction, the $L_{\mathrm{a}, \max }$ decreases as the story number increases, and the values are obviously greater than $\mathrm{X}$ and $\mathrm{Y}$ directions at each story. This also states the vertical vibration induced by subway is prominent than other directions on the slabs of buildings.

5.6. The Distribution of Vibration Level on Velocity Indicator along the Height-Wise. Also, in order to discern the distribution of velocity indicator along the high-wise, onethird octave spectra of velocities of each evaluation point at the typical story and their average spectra were gained and pictured as Figure 19. Then, the distribution of average maximum frequency velocity level $L_{\mathrm{v}, \max }$ along the highwise was calculated and depicted as Figure 20. Also, only the case of damping ratio equal to $2 \%$ is showed due to the limited space.

From Figures 19 and 20, the similar observations and conclusions can be found and gained as same as Figures 16 and 18 . The only difference between velocity level and the acceleration level is the difference in amplitudes. This is inevitable to calculate different indicators of vibrations.

\section{Conclusions}

This paper mainly includes two parts, the first part had presented the results of subway-induced vibration measured on a construction site at the curved section of Shenzhen Metro line No. 1 in China. The other part, based on the results of the field measurement, had calculated the different vibration indicators and investigated the distribution of vibration level along the high-wise of the building to be built over the site of vertical shaft. Especially, the influence of damping ratio on the vibration level has been studied. By the analysis to the results of field vibration measurement and the dynamic behaviour of the building model under the 


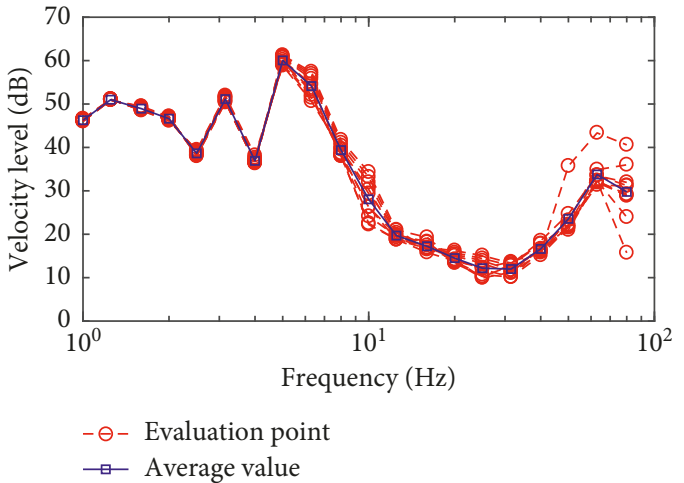

(a)

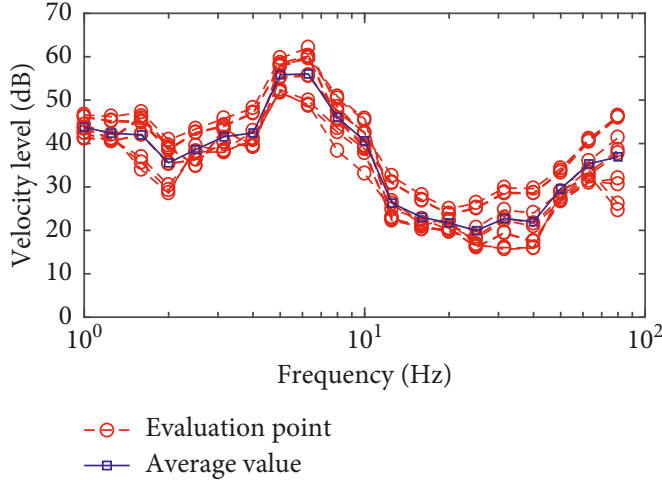

(b)

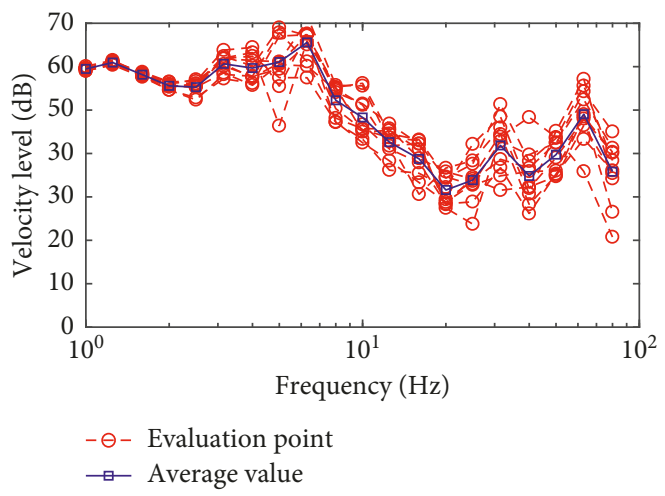

(c)

Figure 19: The $1 / 3$ octave frequency band velocity level of the typical story $\left(6^{\text {th }}\right.$ story, damping ratio $\left.=0.02\right)$. (a) X direction. (b) Y direction. (c) $\mathrm{Z}$ direction.

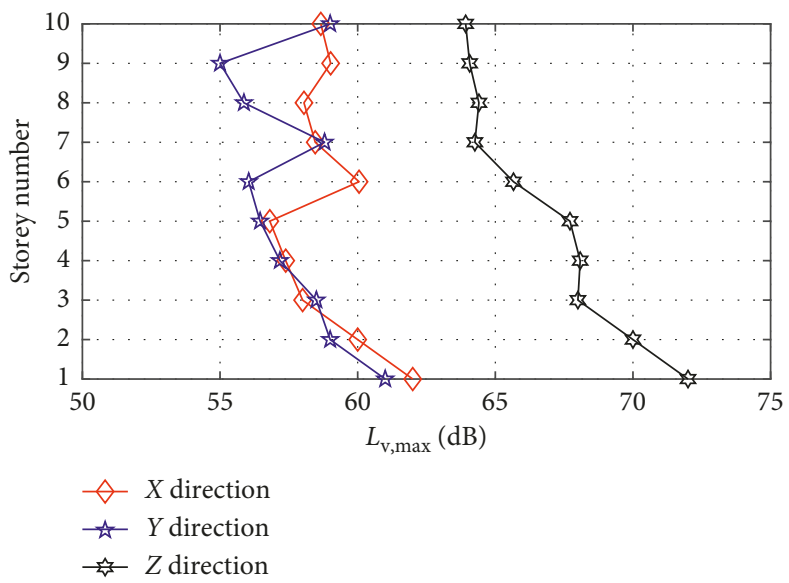

FIgURE 20: The distribution of velocity level along the high-wise (damping ratio $=0.02$ ).

measured accelerations, the following main conclusions were gained.

(1) In the time domain, the subway-induced vibration propagation along direction of perpendicular subway line damped out on the free field as a whole, but there is "rebound phenomenon" at local zone. This is right for $\mathrm{X}$ and $\mathrm{Z}$ direction, but not for $\mathrm{Y}$ direction. In frequency domain, the vibration energy has different distribution at different frequency sections in three directions.

(2) In vertical shaft, the subway-induced vibration of pile top is stronger than the soil site near the pile from view of time domain, and this is right for all three directions. In frequency domain, the vibration energy of two measuring points has its own high and low at different frequency bands. 
(3) For this curved section of the metro line, the most obvious feature is that the vibration in $\mathrm{Y}$ direction is stronger than the other directions on the free field. But for the measuring point of pile top in vertical shaft, the vertical vibration level accords with the straight sections of the metro line and greater than the other directions.

(4) The vibration responses of two evaluation indicators increase as the damping ratio in three directions reduces, and the vertical vibration spectral shapes are obviously different with the spectral shapes of two lateral directions.

(5) For the acceleration level and velocity level, the vertical vibration is more dominant than another two directions at each story of the building, and the maximum frequency vibration levels decrease as the story number increases in vertical direction. But in the two lateral directions, it decreases first, then increases, and then decreases again as the number of stories increase in vertical direction.

\section{Data Availability}

The data used to support the findings of this study are available from the corresponding author or bailigang2008@ 126.com upon request.

\section{Conflicts of Interest}

The authors declare that they have no conflicts of interest.

\section{Acknowledgments}

This work was supported by the National Natural Science Foundation of China (no. 51578273).

\section{References}

[1] X. He, "Environmental vibration induced by urban rail transit system," Journal of Northern Jiaotong University, vol. 21, no. 2, pp. 84-88, 1999.

[2] O. Hassan, Train-Induced Groundborne Vibration and Noise in Buildings, Multi Science Publishing Co Ltd, Brentwood, UK, 2007.

[3] Y. B. Yang and H. H. Hung, "Soil vibrations caused by underground moving trains," Journal of Geotechnical and Geoenvironmental Engineering, vol. 134, no. 11, pp. 16331644, 2008.

[4] A. Eitzenberger, Train-Induced Vibrations in Tunnels: a Review, Luleå Tekniska Universitet, Lulea, Sweden, 2008.

[5] G. Kouroussis, L. V. Parys, C. Conti, and O. Verlinden, "Prediction of ground vibrations induced by urban railway traffic: an analysis of the coupling assumptions between vehicle, track, soil and building," International Journal of Acoustics and Vibration, vol. 18, no. 4, pp. 163-172, 2013.

[6] P. J. Remington, L. G. Kurzweil, and D. A. Towers, "Lowfrequency noise and vibrations from trains," in Transportation Noise Reference Book, Butterworths, London, UK, 1987.

[7] L. G. Kurzweil, "Ground-borne noise and vibration from underground rail systems," Journal of Sound and Vibration, vol. 66, no. 3, pp. 363-370, 1979.
[8] S. Chen, X. Ling, Z. Zhu, F. Zhang, and W. Ma, "Field monitoring on train-induced vibration in the seasonally frozen region of daqing in spring," in Proceedings of International Conference on Transportation Engineering, Chengdu, China, July 2009.

[9] D. Wei, W. Shi, R. Han, and S. Zhang, "Measurement and research on subway induced vibration in tunnels and building nearby in Shanghai," in Proceedings of International Conference on Multimedia Technology (ICMT 2011), Hangzhou, China, July 2011.

[10] W. M. Yan, "Vertical vibration measurement and analysis of buildings on metro train platforms," Journal of Beijing University of Technology, vol. 34, no. 8, pp. 836-841, 2008.

[11] C. Zou, Y. Wang, J. A. Moore, and M. Sanayei, "Train-induced field vibration measurements of ground and over-track buildings," Science of the Total Environment, vol. 575, pp. 1339-1351, 2017.

[12] C. Zou, Y. Wang, P. Wang, and J. Guo, "Measurement of ground and nearby building vibration and noise induced by trains in a metro depot," Science of the Total Environment, vol. 536, pp. 761-773, 2015.

[13] Z. Cao, T. Guo, and Z. Zhang, "Vibration measurement in a metro depot with trains running in the top story," Journal of Vibroengineering, vol. 19, no. 1, pp. 502-519, 2017.

[14] Z. Cao, T. Guo, and Z. Zhang, "Measurement and analysis of vibrations in a residential building constructed on an elevated metro depot," Measurement, vol. 125, no. 1, pp. 394-405, 2018.

[15] H. Zhou, W. He, and W. Xie, "Research on vibration serviceability of over-track buildings," in Proceedings of Second International Conference on Transportation Information and Safety, pp. 621-626, Wuhan, China, June 2013.

[16] P. Lopes, P. A. Costa, R. Calçada, and A. S. Cardoso, "Influence of soil stiffness on building vibrations due to railway traffic in tunnels: numerical study," Computers and Geotechnics, vol. 61, pp. 277-291, 2014.

[17] P. Lopes, P. A. Costa, R. Calçada, and A. S. Cardoso, "Numerical modeling of vibrations induced by railway traffic in tunnels: from the source to the nearby buildings," Soil Dynamics and Earthquake Engineering, vol. 61-62, pp. 269-285, 2014.

[18] P. Lopes, J. F. Ruiz, P. A. Costa, R. Calçada, and A. S. Cardoso, "Vibrations inside buildings due to subway railway traffic. Experimental validation of a comprehensive prediction model," Science of the Total Environment, vol. 568, pp. 1333-1343, 2016.

[19] D. Lopez-Mendoza, A. Romero, D. P. Connolly, and P. Galvín, "Scoping assessment of building vibration induced by railway traffic," Soil Dynamics and Earthquake Engineering, vol. 93, pp. 147-161, 2017.

[20] P. Coulier, G. Lombaert, and G. Degrande, "The influence of source-receiver interaction on the numerical prediction of railway induced vibrations," Journal of Sound and Vibration, vol. 333, no. 12, pp. 2520-2538, 2014.

[21] S. Gupta, G. Degrande, and G. Lombaert, "Experimental validation of a numerical model for subway induced vibrations," Journal of Sound and Vibration, vol. 321, no. 3-5, pp. 786-812, 2009.

[22] D. P. Connolly, G. Kouroussis, O. Laghrouche, C. L. Ho, and M. C. Forde, "Benchmarking railway vibrations-track, vehicle, ground and building effects," Construction and Building Materials, vol. 92, pp. 64-81, 2015. 
[23] J. P. Yang, P. Z. Li, and Z. Lu, "Numerical simulation and insitu measurement of ground-borne vibration due to subway system," Sustainability, vol. 10, no. 7, p. 2439, 2018.

[24] Y. Wang, Research on the Acquisition and Procession of Strutural Vibration Signal, School of Civil Engineering, Tongji University, Shanghai, China, 2006.

[25] V. H. Nguyen, J. Mahowald, S. Maas, and J. C. Golinval, "Use of time- and frequency-domain approaches for damage detection in civil engineering structures," Shock and Vibration, vol. 2014, Article ID 872492, 9 pages, 2014.

[26] R. Shao, W. Hu, and J. Li, "Multi-fault feature extraction and diagnosis of gear transmission system using time-frequency analysis and wavelet threshold de-noising based on EMD," Shock and Vibration, vol. 20, no. 4, pp. 763-780, 2013.

[27] MATLAB, Version R2015a [Software]. 2015, The Math Works Inc., Natick, MA, USA, 2015.

[28] Pennsylvania State University, Mechanical Vibration and Shock-Evaluation of Human Exposure to Whole-Body Vibration-Part 1: General Requirements, Pennsylvania State University, Harrisburg, PA, USA, 1997.

[29] M. Vibration, "Shock-evaluation of human exposure to whole-body vibration-part 2: vibrations in buildings ( 1 to 80 $\mathrm{Hz})$," International Standard ISO, Geneva, Switzerland, 2003.

[30] C. E. Hanson, D. A. Towers, and L. D. Meister, Transit Noise and Vibration Impact Assessment, Federal Transit Administration, Office of Planning and Environment, Washington, DC, USA, 2006.

[31] I. Idriss, Quad-4: A Computer Program for Evaluating the Seismic Response of Soil Structures by Variable Damping Finete Element Procedures, University of California, Berkeley, CA, USA, 1973. 


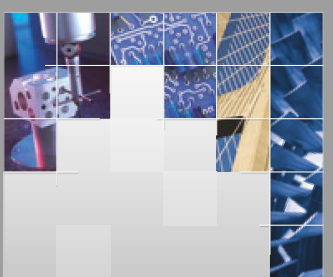

\section{Enfincering}
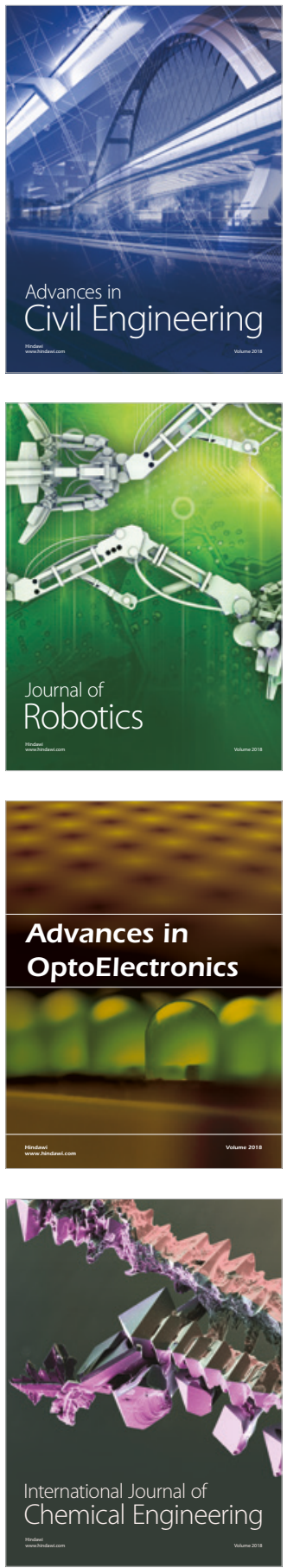

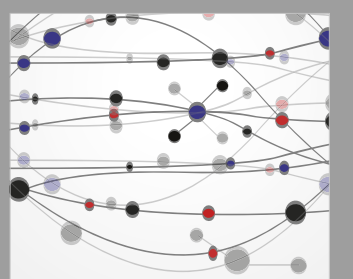

\section{Rotating \\ Machinery}

The Scientific World Journal

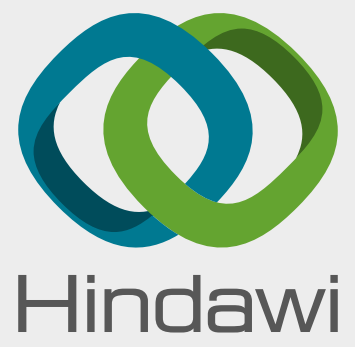

Submit your manuscripts at

www.hindawi.com
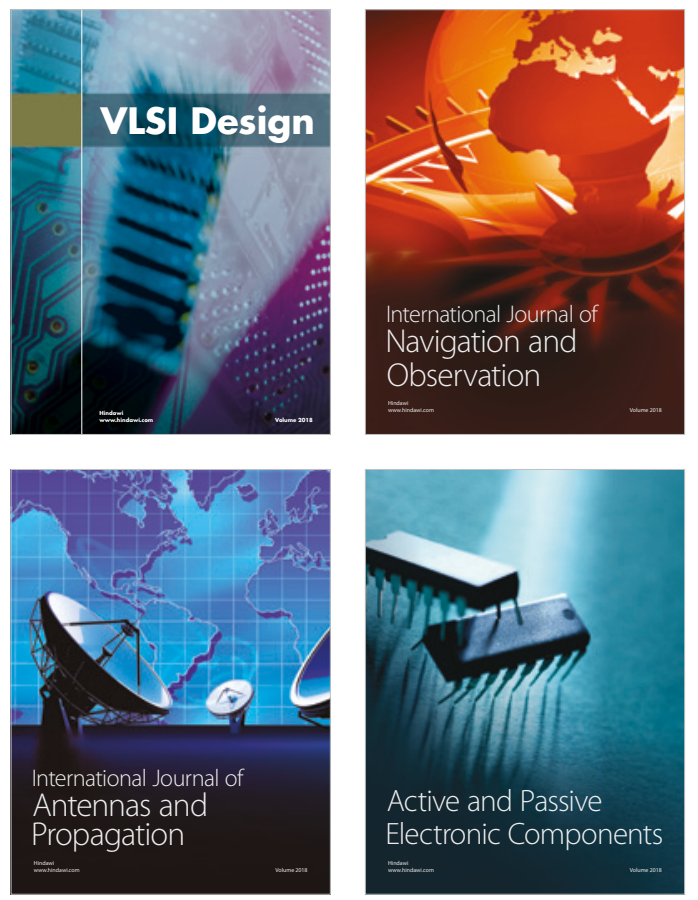
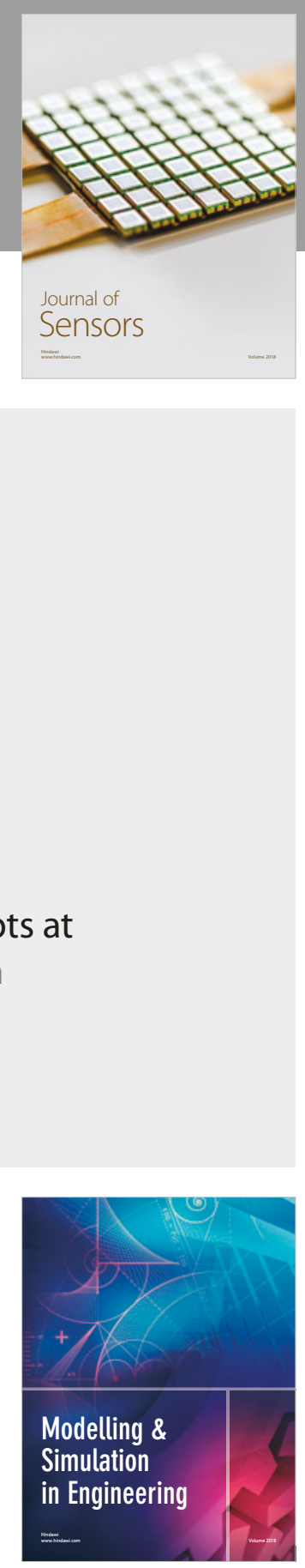

\section{Advances \\ Multimedia}
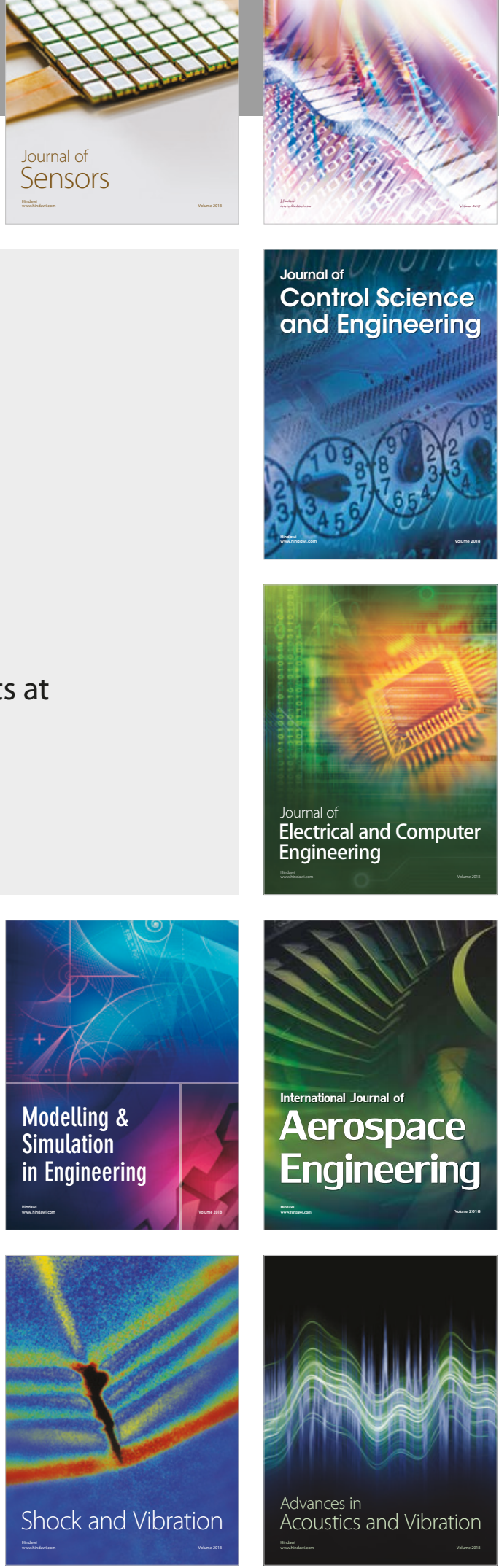